\title{
Uterine Malformations: Diagnosis with 3D/4D Ultrasound
}

\author{
${ }^{1}$ Fernando Bonilla-Musoles, ${ }^{2}$ Noemi Martin, ${ }^{3}$ Mari Pepa Esquembre, ${ }^{4}$ Oscar Caballero, ${ }^{5}$ uan Carlos Castillo, \\ ${ }^{6}$ Francisco Bonilla J r, ${ }^{7}$ Francisco Raga, ${ }^{8}$ Luiz Eduardo Machado
}

\begin{abstract}
The development of the female genital system is a complex embryological process. Congenital malformations of the female genital tract may occur isolated or in combination with urologic defects. The aim of this review is to describe novel ultrasonographic advances to improve diagnostic accuracy of Müllerian malformations and to facilitate decisions about treatment and prognosis.
\end{abstract}

Keywords: Congenital uterine malformations, Female reproductive tract, Müllerian anomalies, Three-dimensional ultrasonography.

How to cite this article: Bonilla-Musoles F, Martin N, Esquembre MP, Caballero O, Castillo J C, Bonilla F J r, R aga F, Machado L. Uterine Malformations: Diagnosis with 3D/4D Ultrasound. Donald S chool J Ultrasound Obstet Gynecol 2015;9(2):123-148.

\section{Source of support $\mathrm{Nil}$}

Conflict of interest: None

\section{INTRODUCTION}

They are a heterogeneous group of congenital anomalies that result from a failure in one of the three development phases of the paramesonephric or Müller ducts:

- Organogenesis phase: One or both Müllerian ducts are not fully developed, leading to anomalies, such as agenesis, bilateral or unilateral uterine aplasia (unicornuate uterus).

- Fusion phase: The process during which the distal segments of the Müllerian ducts fuse to form the uterus, cervix and upper third of the vagina, is called the lateral fusion. A failure, abnormal fusion or incomplete fusion result in a uterus didelphus or bicornuate uterus.

- The septum resorption phase: After the fusion, the central septum is reabsorbed leading to just one endometrial

\footnotetext{
${ }^{1,8}$ P rofessor, ${ }^{2,5,7}$ Consultant, ${ }^{3}$ Fellow, ${ }^{4}$ Lecturer, ${ }^{6}$ AssistantP rofessor

1-3,6-8 Department of Obstetrics and Gynecology, School of Medicine, University of Valencia, Avenida Blasco Ibáñez, Valencia Spain

${ }^{4}$ Biocontrol e Investigación Institute, Valencia, Spain

${ }^{5}$ Human Assisted Reproduction Unit, Instituto Bernabeu, Av. Albufereta 31, Alicante, Spain
}

Corresponding Author: Fernando Bonilla-Musoles, Professor Department of Obstetrics and Gynecology, School of Medicine University of Valencia, Avenida Blasco Ibáñez 17,46011, Valencia Spain, e-mail: pofesorbonilla musoles@ hotmail.com cavity and just one cervix. If reabsorption does not take place, it results in septate uterus that may or may not reach into the vagina.

- Finally, and independent of the above three phases, there is an association between these and kidney abnormalities because urinary system development is closely associated. ${ }^{1}$

The female genital tract is developed from paramesonephric ducts (Müller) which begin to elongate caudally until their lower portion meets in the midline to create the uterus, cervix to the external os and upper portion of the vagina while the unfused upper portions leads to the Fallopian tubes.

Altough Wolff ducts will dissapear, they are needed to the right development as they act as guide element for the Müllerian ducts.

Wolff's duct is reabsorbed cranially but thickeing their lower portion from external cervical os, lead the sinuvaginales bulbs, incorporate Müller's tuber cells and lead the vaginal plate whose cavitation and epidermization from the vagina. ${ }^{2-5}$

Müller ducts begin to elongate caudally and their lower portion joins the medial wall of mesonephric ducts within a common basement membrane leading to Müller's tubercle in the dorsal wall of urogenital sinus.

The vagina is the genital organ whose embryology is more controversial. The classical theory suggests that its upper portion derives from Müller duct and the lower portion from urogenital sinus. Besides the role of Wolff's ducts as an inductor, several studies have proven that their caudal portions are involved in the formation of the vagina (sinuvaginales bulbs) ${ }^{2}$ (Fig. 1).

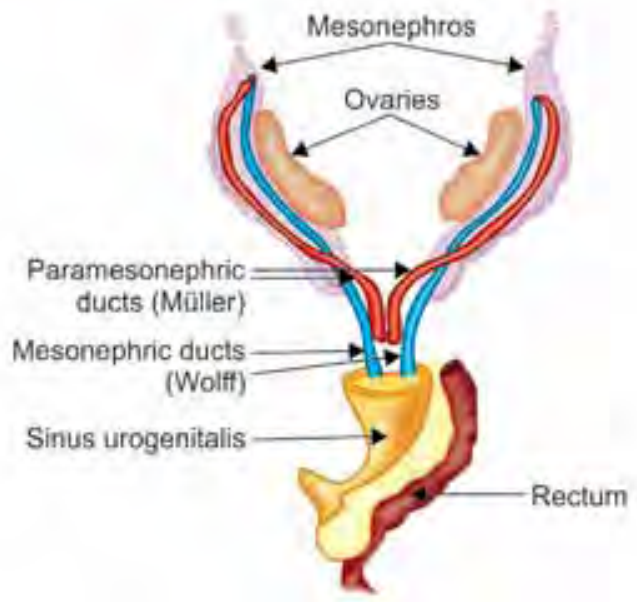

Fig. 1: Embryology of the female genital tract 


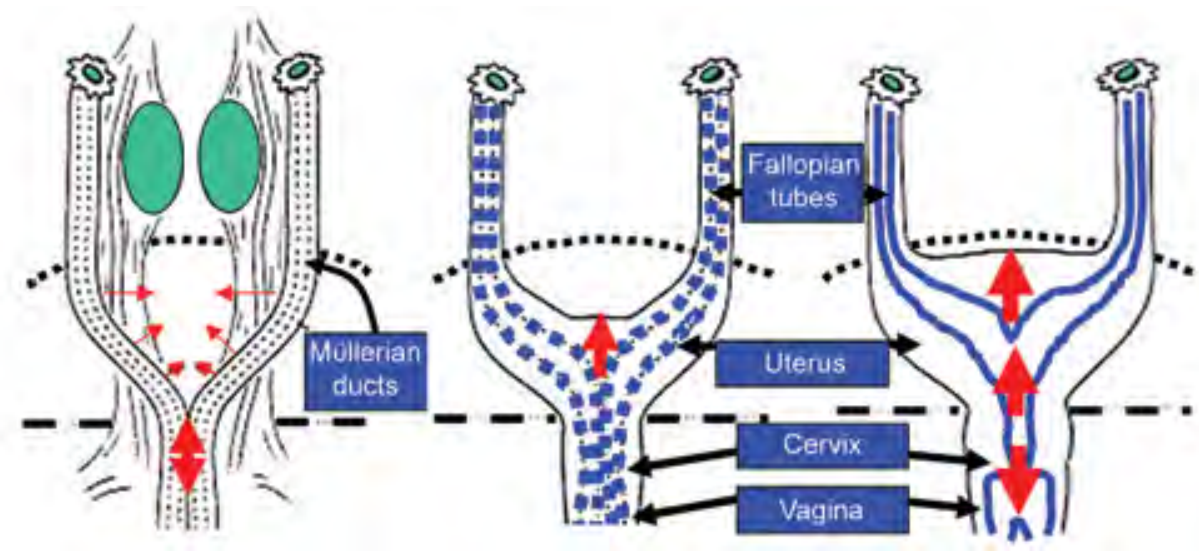

Fig. 2: Duct canalization

Canalization of the vaginal duct will be complete around week 20 to 22nd of pregnancy (Fig. 2).

Besides pregnancies at term have been described in unicornuate and didelphys uterus, most complications of these malformations appear in the field of reproductive medicine, but also present with gynecological problems such as amenorrhea, dismenorrhea, or other kind of problems if urological anomalies are associated..$^{6-8}$

Many women with these abnormalities are asymptomatic while others experience a variety and degree of manifestations that can occur at any age, and generally depend on the type of anomaly and of reproductive age. The following are the most common: ${ }^{1}$

- Amenorrhea in Müllerian agenesis.

- Dismenorrhea in obstructive anomalies.

- Menstrual bleeding in communicating uteri.

- Repeated misacarriage and obstetrics complications in cases of fusion and reabsorption anomalies (infertility, fetal malposition, ectopic pregnancy). ${ }^{5,6}$

- Pelvic tumors caused by menstrual remains and endometriosis.

- Associated urinary and skeletal malformations.

Müllerian malformations commonly involve uterine defects and this is why they are also known as uterine or paramesonephric anomalies. However, many are also mesonephric in origin and will have renal malformations as well.

\section{PREVALENCE}

Prevalence is difficult to establish because of the lack of a uniform classification system and the use of different diagnostic methods.

It is estimated to occur in $0.4 \%$ of the population, ${ }^{7-10}$ but the percentage increases in infertile patients 4 to $10 \%,{ }^{7-11}$ or women who have repeated miscarriages, 3 to $38 \%$., 3,8,12-15

Our work shows that $6.3 \%$ of infertile women have a Müllerian abnormalities (Table 1).

Incidence of uterine malformations between patients with reproductive desire. ${ }^{2,3}$
Table 1: Incidence of uterine malformations among patients with desire conception in reproductive age

\begin{tabular}{lllll}
\hline $\begin{array}{l}\text { Type of } \\
\text { malformation }\end{array}$ & $\begin{array}{l}\text { Fertility } \\
(\mathrm{n}=1289)\end{array}$ & $\begin{array}{l}\text { Infertility } \\
(\mathrm{n}=868)\end{array}$ & $\begin{array}{l}\text { Sterility } \\
(\mathrm{n}=1024)\end{array}$ & $\begin{array}{l}\text { Total } \\
(\mathrm{n}=3181)\end{array}$ \\
\hline II unicornis & $2(0.2)$ & $5(0.6)$ & $1(0.1)$ & $8(0.3)$ \\
a & 0 & 1 & 0 & 1 \\
$\mathrm{~b}$ & 0 & 3 & 0 & 3 \\
$\mathrm{c}$ & 1 & 0 & 0 & 1 \\
d & 1 & 1 & 1 & 3 \\
III didelphus & $1(0.1)^{\mathrm{c}}$ & $6(0.7)^{\mathrm{b}}$ & $1(0.1)$ & $8(0.3)^{\mathrm{c}}$ \\
IV bicornis & $5(0.4)^{\mathrm{e}}$ & $16(1.9)^{\mathrm{d}}$ & $5(0.5)^{\mathrm{e}}$ & $26(0.7)^{\mathrm{c}}$ \\
a & 0 & 7 & 1 & 8 \\
b & 5 & 9 & 4 & 18 \\
V septum & $20(1.5)$ & $17(2)$ & $6(0.6)$ & $43(1.4)^{\mathrm{b}}$ \\
a & 4 & 6 & 0 & 10 \\
b & 16 & 11 & 6 & 33 \\
VI arquatus & $21(1.6)$ & $9(1.0)$ & $12(1.1)$ & $42(1.3)^{\mathrm{b}}$ \\
VII DES & 0 & $1(0.1)$ & 0 & 1 \\
Total & $49(3.8)^{\mathrm{e}}$ & $54(6.3)^{\mathrm{b}}$ & $25(2.4)^{\mathrm{c}}$ & $128(4.0)$ \\
\hline b/c Significant & & & & 0
\end{tabular}

$\mathrm{b} / \mathrm{c}$ Significant values $(p<0.05)$; d/e Significant values $(p<0.05)$

A recent revision including studies using advanced diagnostic tools shows a $\sim 7 \%$ prevalence in general population. ${ }^{16}$ The introduction of transvaginal ultrasound in clinical practice represented a substantial step forward; more recently, three-dimensional ultrasonography has added new insights.

\section{CLASSIFICATION}

The most basic classification divides these malformations in three groups: ${ }^{17}$

- Agenesis

- Vertical fusion defects

- Lateral fusion defects.

This basic classification of uterine anomalies has generated much confusion since many researchers used the term hemi uterus to refer to unicorn uterus, double uterus and both bicornuate uterus as septate uterus. In 1979, a new classification for uterine malformations based 


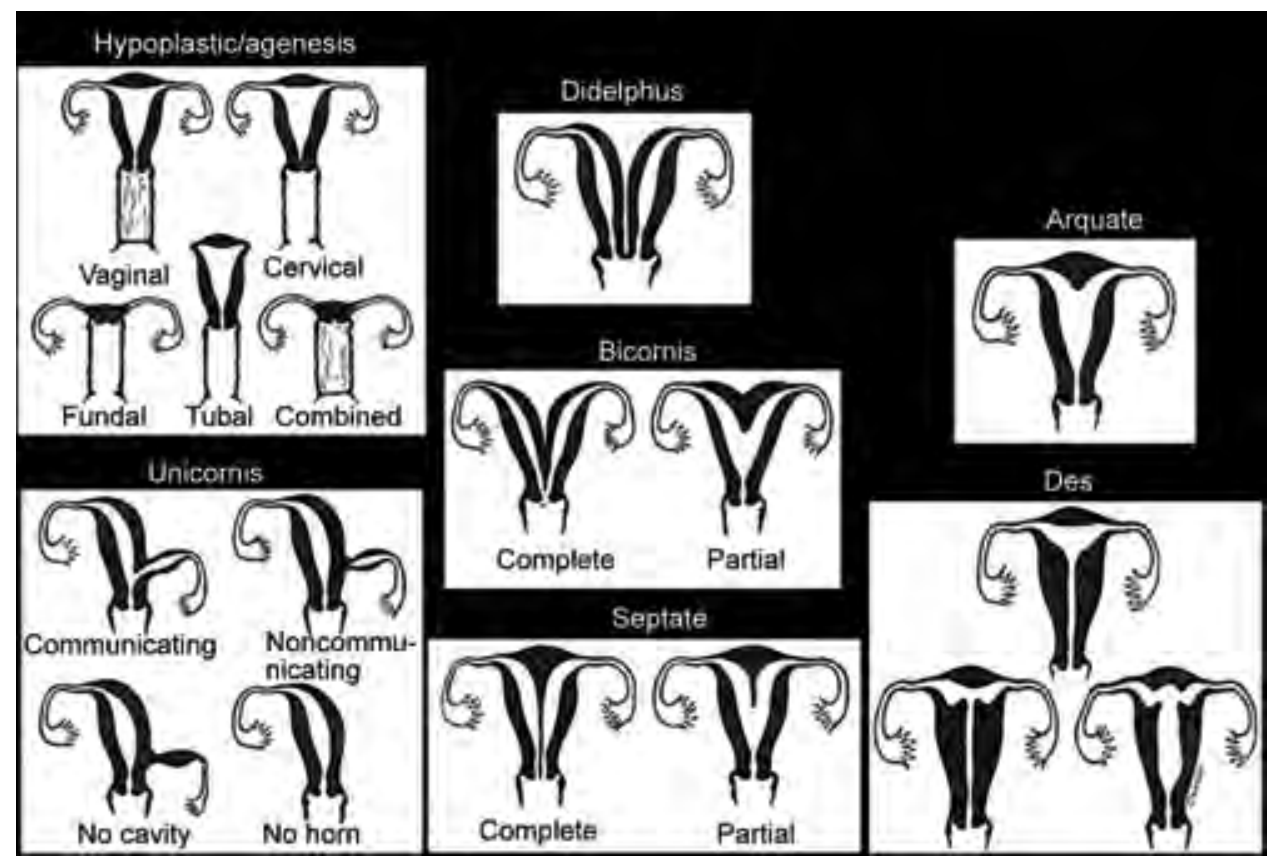

Fig. 3: The American Fertility Society classification ${ }^{19}$

on failure of development and associated anomalies in groups with identical clinical manifestations, treatment and prognosis ${ }^{18}$ was proposed. In 1983, the American Fertility Society (AFS), now American Society for Reproductive Medicine (ASRM), proposed to qualify the above described classification with very few modifications in $1988^{19}$ (Fig. 3).

Seven groups are included in this classification of the lates 1980's. It is useful but incomplete because other associated anomalies are not mentioned (e.g. communicating uteri, etc.).

\section{Group I: Hypoplasia/Agenesis}

- Vaginal agenesis: It is a very rare malformation with a incidence of 1:10000 cases. The external genitalia, fallopian tubes and ovaries are normal. The cervix is hypoplastic or absent, and the uterine cavity may be normal or show any abnormalities. Ultrasound scan allows us to differentiate from Rockitansky's syndrome which has uterine agenesis. Also, testicular feminization can be excluded as no ovarian tissue are visible.

- Cervix agenesis with uterine cavity and functional endometrium, is exceptional. Over 50\% other Müllerian anomalies associated (most common bicornuate uterus).

- Fundus agenesis is associated with primary amenorrhea and/or infertility. Ultrasound shows rudimentary or absent uterine cavity in a woman with normal external genitalia, normal or hypoplastic cervix with normal ovaries (Fig. 4).

- Fallopian tubes agenesis.
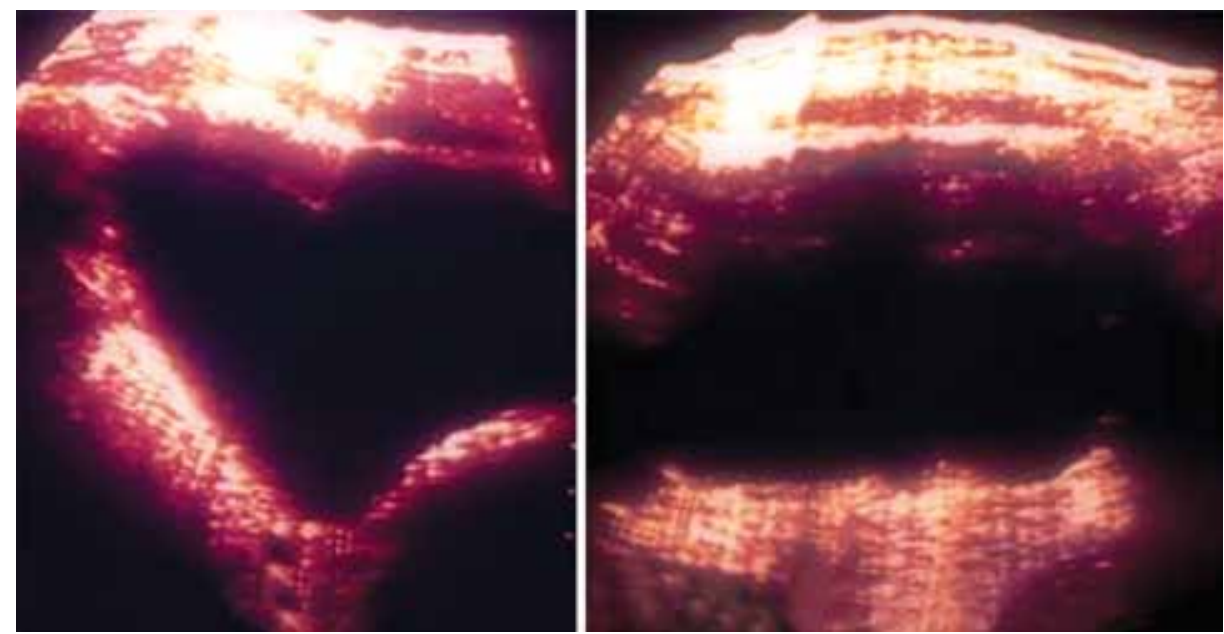

Fig. 4: Rokitansky syndrome. Absence of uterus. Abdominal 2D US. To the left longitudinal cut at the vesical level. To the right transversal cut. No uterus is visible 


\section{Group II: Unicornuated Uterus}

It is the result from the development of just one of the Müller's duct while the other is not developed or it may be partially developed and connected or not to the uterus.

Three-dimensional ultrasound shows uterine endometrial cavity with its volume decreased, and let us check if the authentic rudimentary horn has functional endometrium and if they are communicated or not.

They frequently are associated to kidney agenesis.

Therefore, the different possibilities are the following:

- Unicornuate uterus with rudimentary horn communicated and functional endometrium (IIa),

- Unicornuate uterus with rudimentary horn but not communicated with functional endometrium (IIb), (Fig. 5). Unicornuated uterus with no functional rudimentary horn (IIc),

- Unicornuated uterus (IId) (Figs 6 to 8).

\section{Considerations}

It is considered the rarest Müllerian anomaly. Many case reports and reviews have been published in medical literature and despite a 'typical' radiologic image is almost universally reproduced in hysterosalpingographic text books, little clinical information is described.

\section{Types}

The authentic unicornuate, characterized by a complete absence of duct development, associated to a partial/total absence of the ipsilateral tube; and plausibly (at least in theory) with ovarian absence as well.

In the second type a hemiuterus or a rudimentary horn also co-exists; this is considered by many authors as a bicornuate uterus with a rudimentary horn. These 'pseudo' unicornuate uteri are more common than the authentic ones.

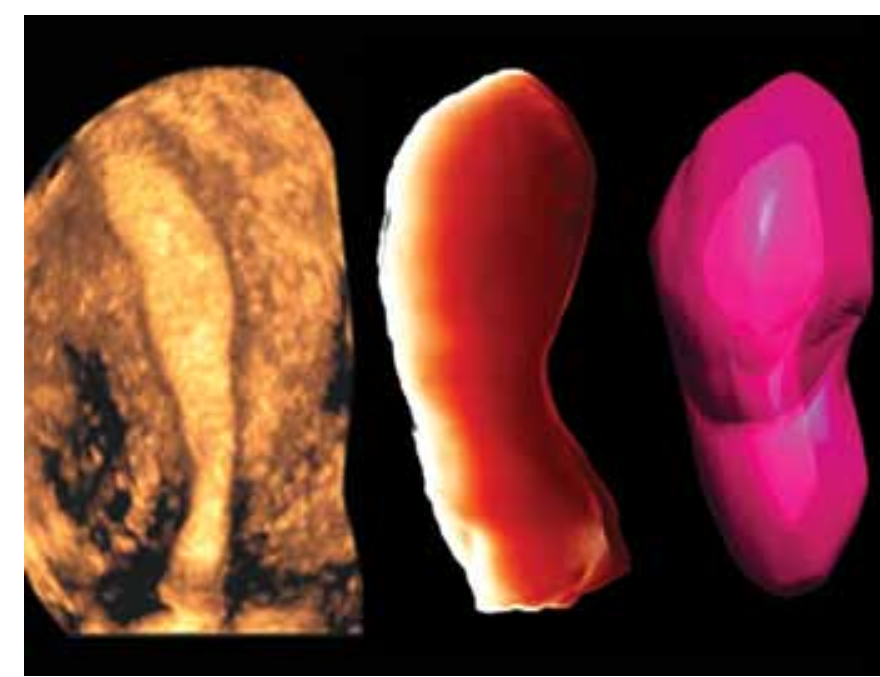

Fig. 6: Unicornuated uterus. There is only one horn and no rudimentary cavity. It is showed with $3 \mathrm{D}$ ultrasound, HD live and a Vocal

\section{Morphology}

Radiologic studies describe two relevant types of uterine cavities in unicornuate uteri: the fusiform and the 'guadaña' form (resembling the shape of an ancient farm tool) which has a convexity on one side. Also, intermediate forms have been described. Noticeable, sometimes a filiform cervical canal is encountered.

\section{Kidney Abnormalities}

Unicornuate uteri are often associated to unilateral kidney agenesis or other urinary anomalies (e.g. ptosis, duplicity, etc.).

\section{Obstetric Issues}

Unicornuate uteri have the same obstetric complications associated to Müllerian malformations, but not limited to: miscarriage, premature delivery, c-section.

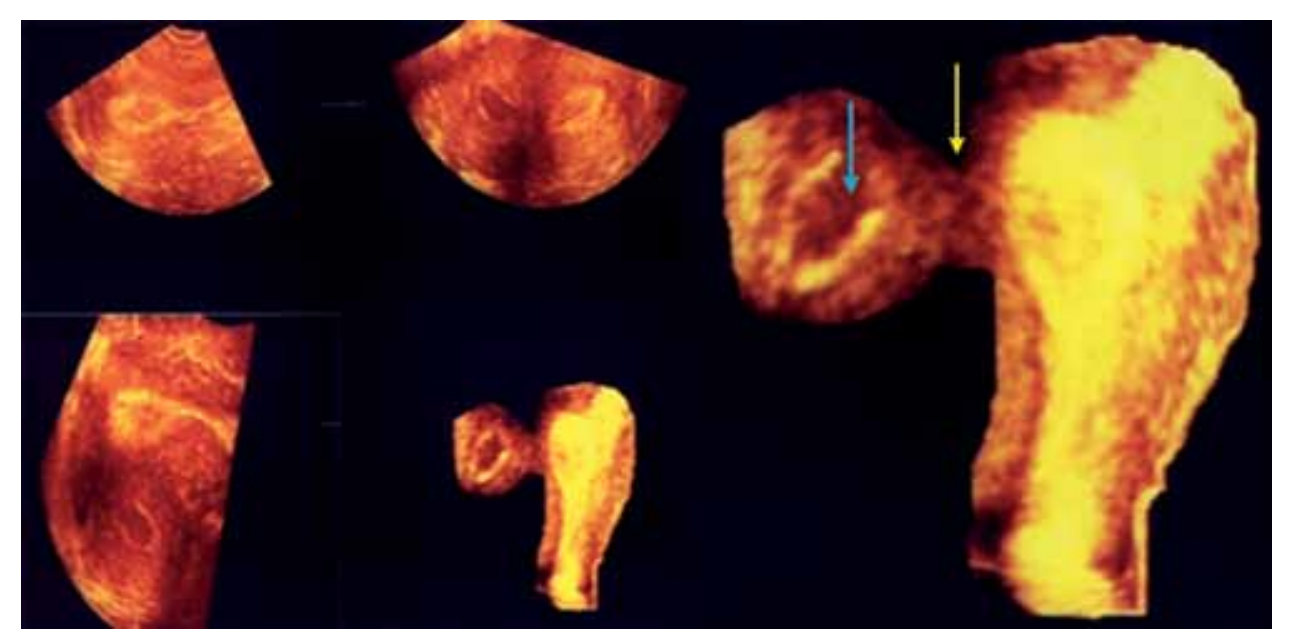

Fig. 5: Unicornuate uterus with rudimentary horn which has cavity (blue arrow) but not communicated (yellow arrow) 


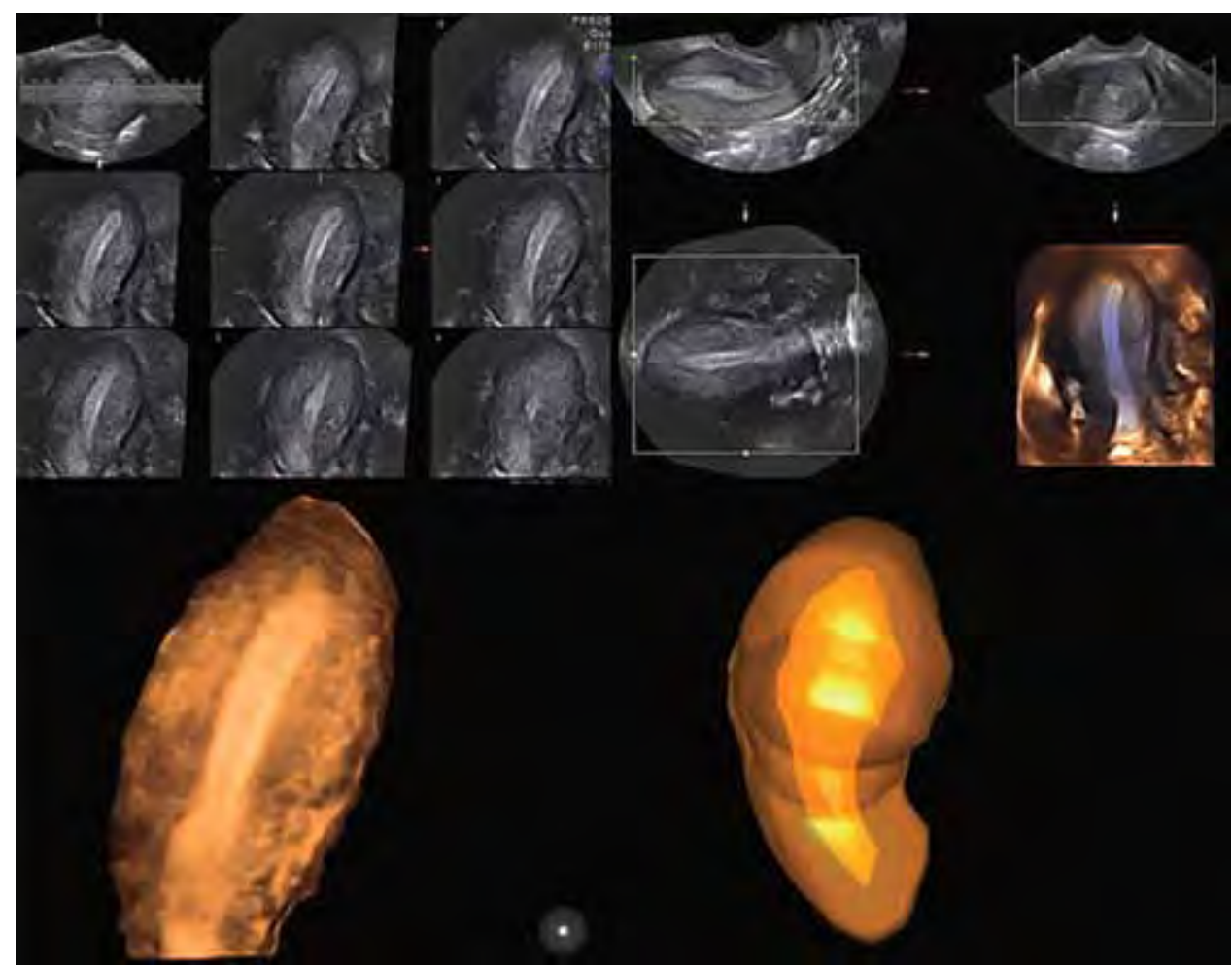

Fig. 7: Unicornuated uterus. It is the most uncommon variety. At the top with TUI and 4D HDLive. In the bottom with magic cut and Vocal

\section{Group III: Didelphys Uterus}

It is the result of the failure of both ducts fusion midline. Each hemiuterus develops complete but independently leading to duplication of the genital system.

This anomaly is usually associated with the presence of a longitudinal vaginal septum in $75 \%$ of cases.

Three-dimensional reveals two hemiuteri and two cervix. Uterine bodies are presented as a mirror image, with a deep fundal separation (Fig. 9).

\section{Group IV: Bicornuated Uterus}

This type derives from a failure of the fusion of both Müller's duct at the fundus. We can see two endometrial cavities that get joined near the cervix, typically presenting a 'notch' at this level between the two uterine horns.

Depending on the slit extends partially (IVb) or completely (IVa), two varieties are covered with different reproductive prognosis.

Three-dimensional ultrasound has allowed differentiate from septal uterus without performing a diagnostic laparoscopy. The slot must be greater than $10 \mathrm{~mm}$ to differentiate septate uterus. We can use more innovative methods to do a more accurate diagnosis such as: magic cut, scissor, TUI or Doppler angiography.

Figures 10 and 11 show typical 3D pictures of a partial (variety IVb) and a total bicornis uteri (variety IVc).

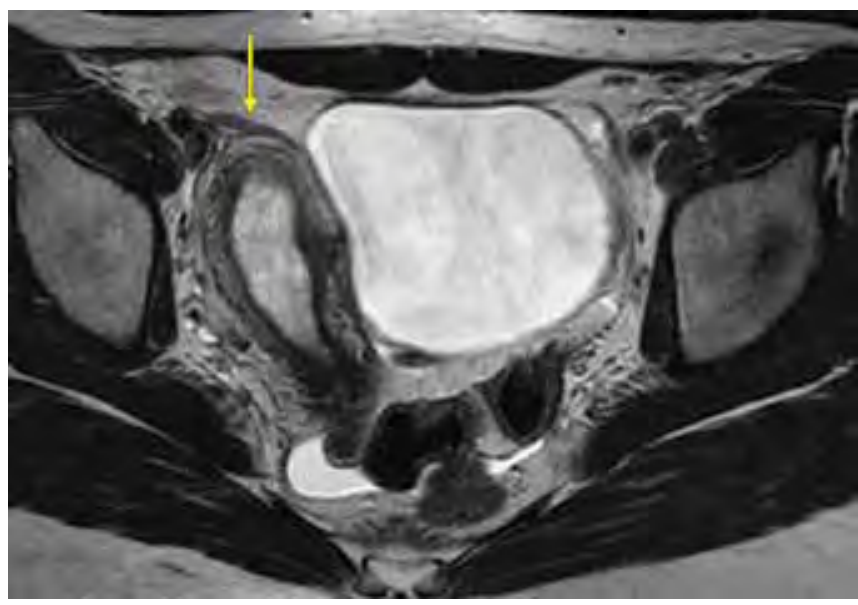

Fig. 8: MRN of the same patient. Unicornuate uterus is marked by yellow arrow

Figures 12 and 13 show typical 3D pictures of a total bicornis uteri (variety IVa).

In this variety, the ASRM classification type IVa admits the possibility that there are two independent cervix (Fig. 3).

For many decades-when hysterosalpingography was used as diagnostic tool, this type of malformation was frequently mistaken by a septum uterus, only laparoscopic procedures were reliable for a correct differential diagnosis.

Therefore, 3D ultrasound has become so important, because it allows to differentiate these two anomalies accurately. With 3D study we will see a united endometrial cavity near cervix but separated at fundus. 


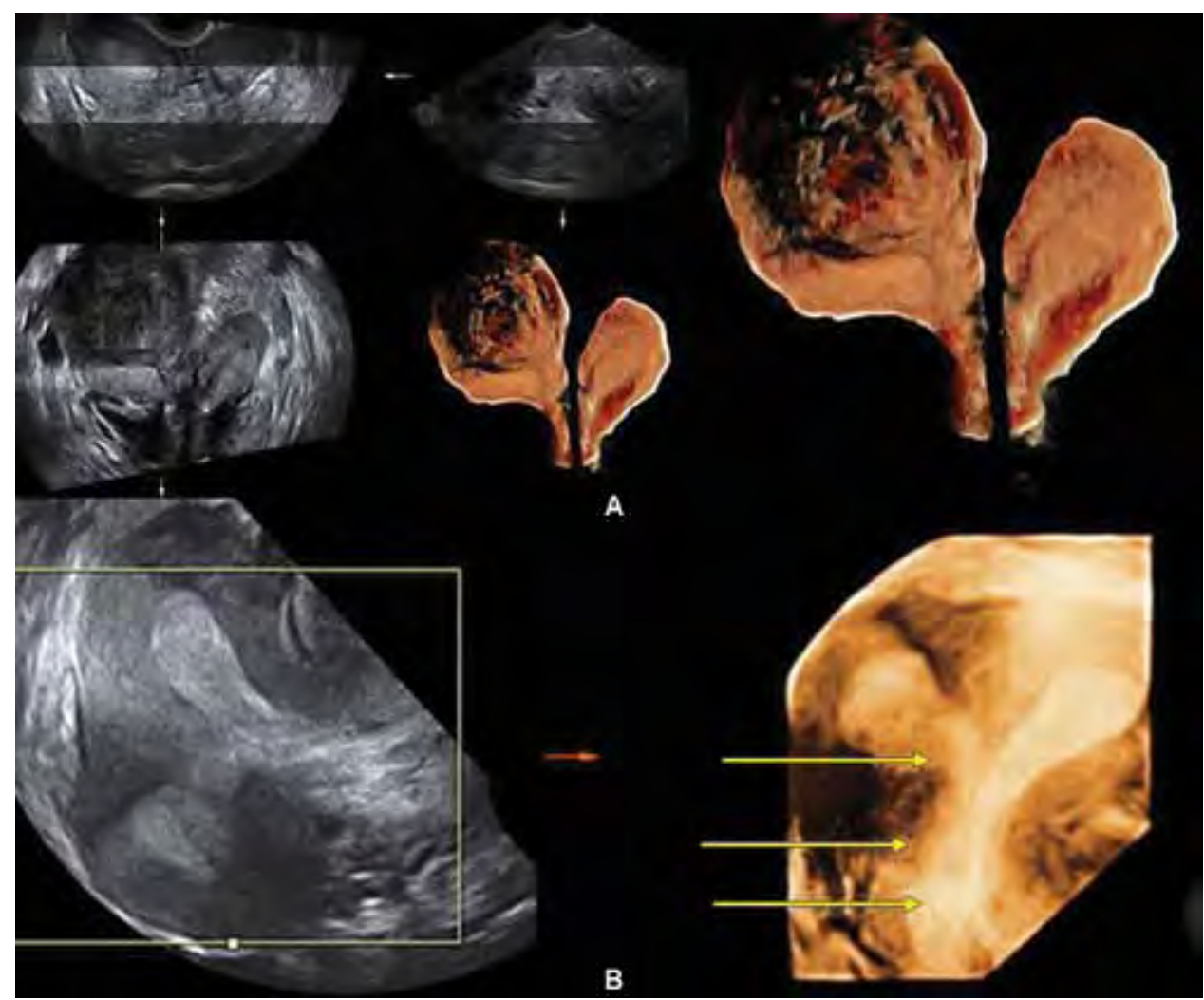

Fig. 9: In A, didelphys uterus, scissors system. In B, arrows indicate the two hemiuterus, cervix and vagina. The 2D images are not demonstrative, 3D images do demonstrate

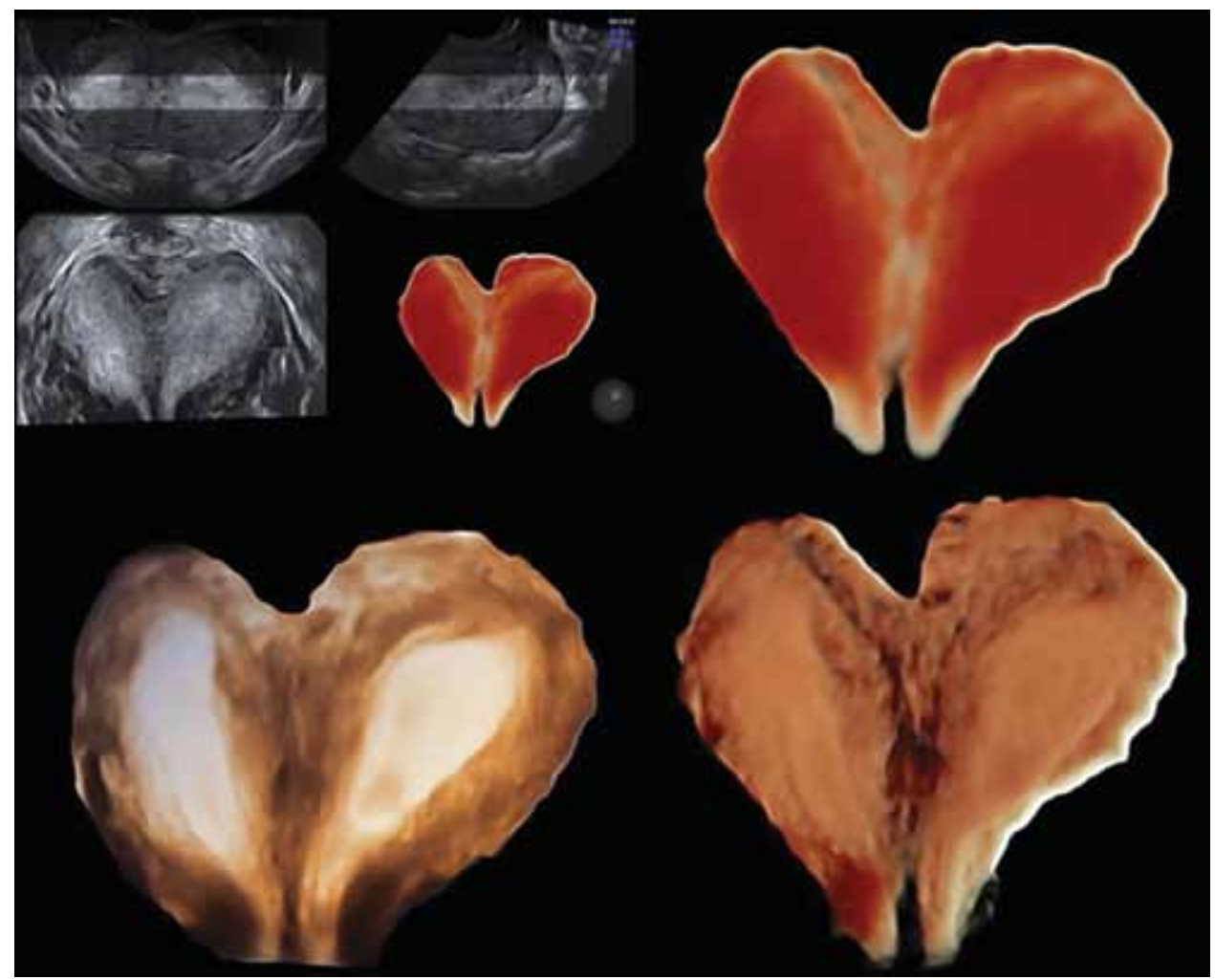

Fig. 10: Total bicornuate uterus observed with HDLive (variety IVc)

Morphology uterine fundus to appreciate a slit between the two cavities which must be greater than $10 \mathrm{~mm}$ to allow differential diagnosis with arcuate uterus.
For differential diagnosis, we can use other ultrasound modes which hardly exists in the literature contributions; magic cut; TUI digital angiography and Doppler (Fig. 14). 

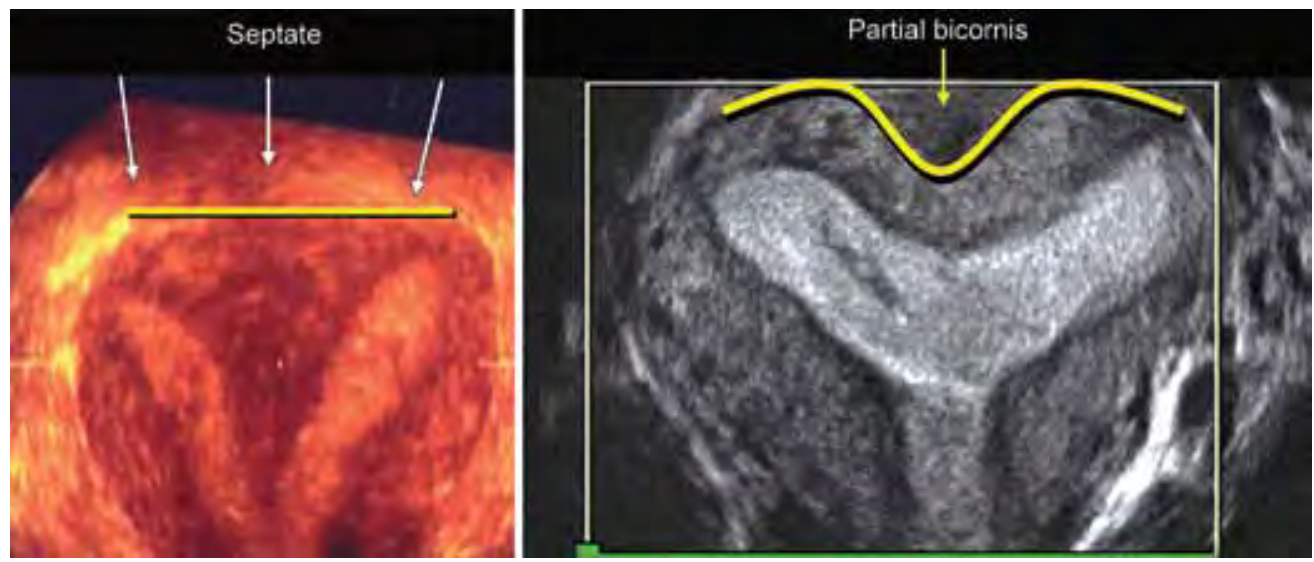

Fig. 11: On the left, complete septate uterus, note the linear fundus (arrows). On the right, partial bicornuate uterus (variety IV b). Three dimensional image on the front shows the angle separation of the two horns in the uterine fundus, which exceeds $10 \mathrm{~mm}$ (line and yellow arrow)

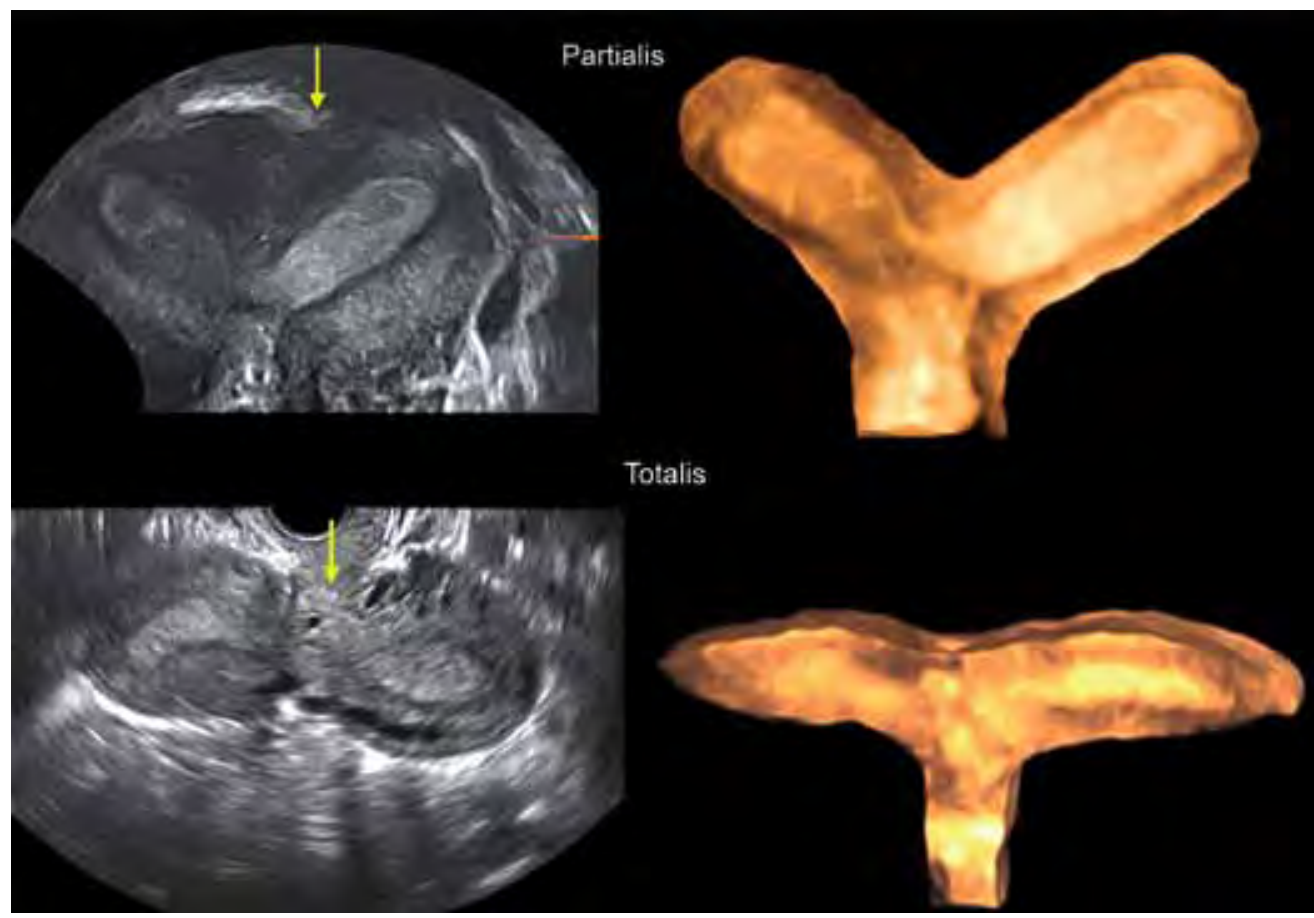

Fig. 12: Two-dimensional ultrasound and 3D images with magic cut. A clear view of the separation between the two horns can be observed in orthogonal planes as well as in 3D magic cut view
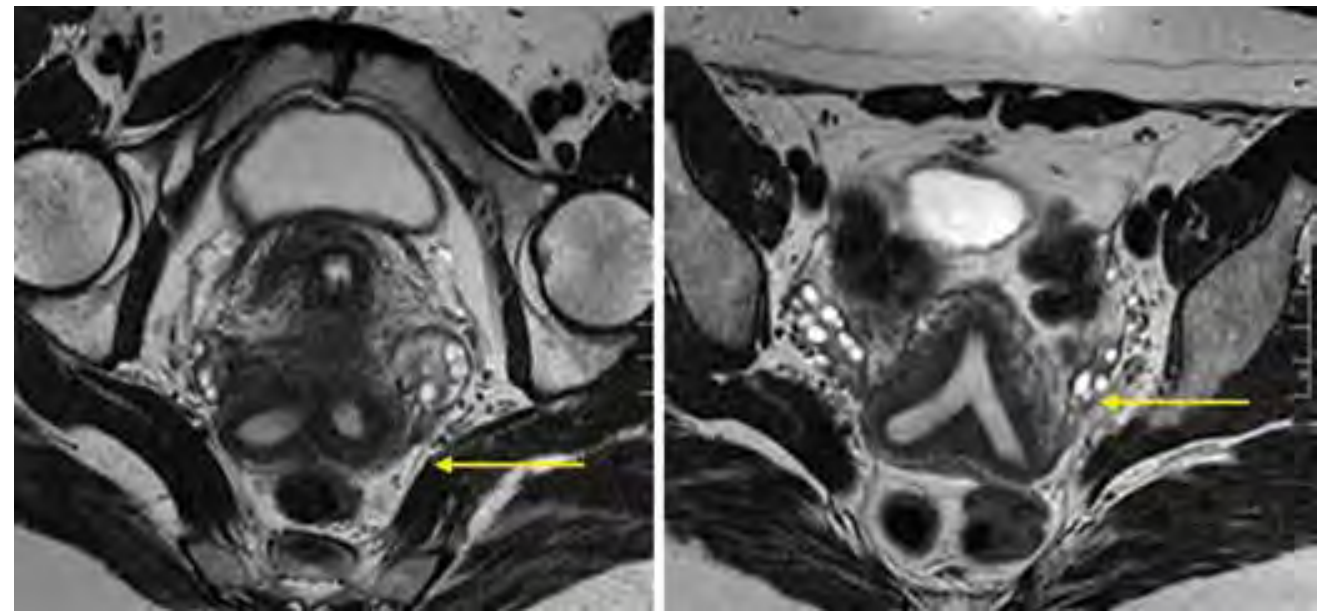

Fig. 13: MRN of bicornuate uterus showed in Figure 12 (yellow arrows) 


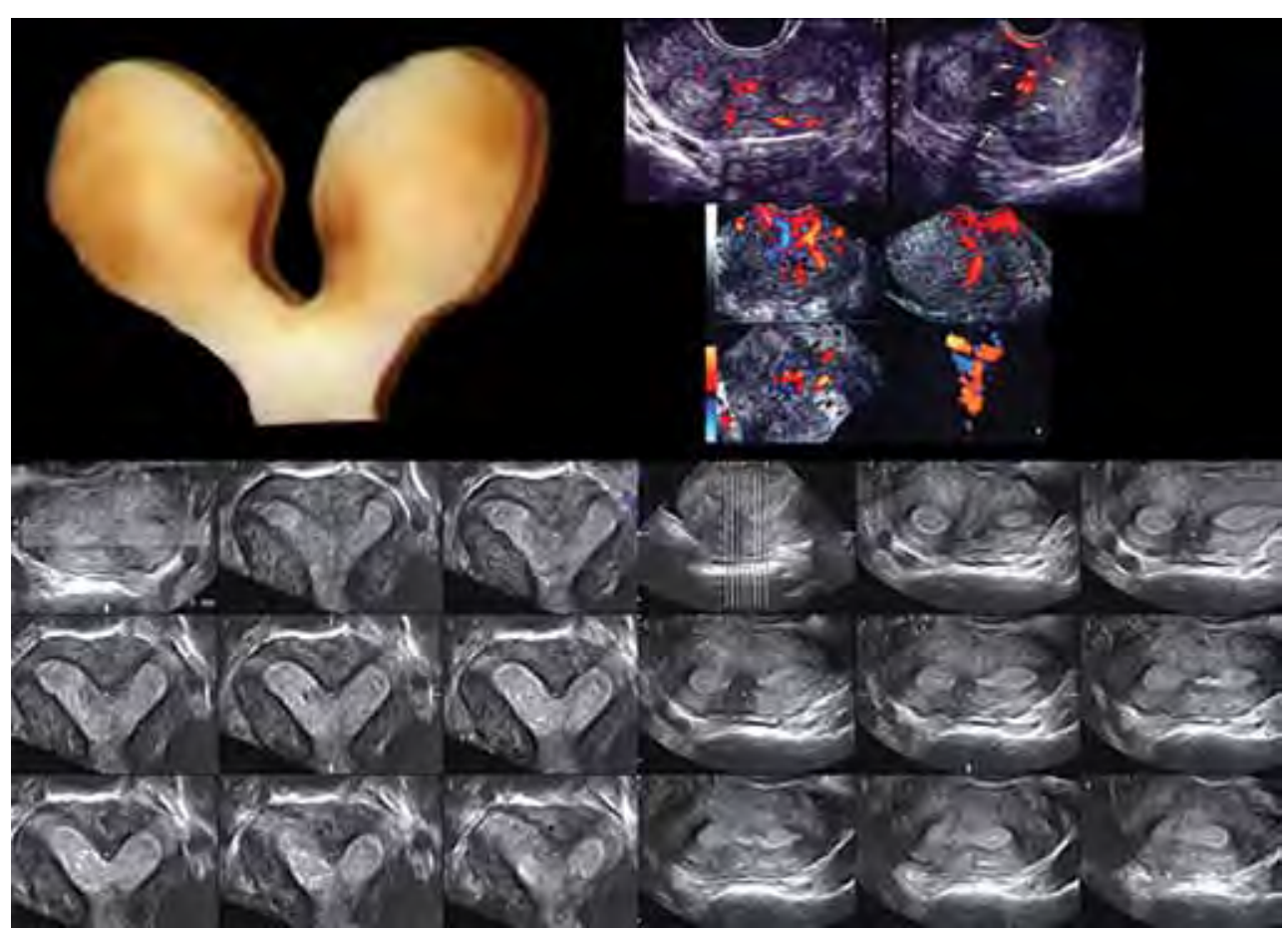

Fig. 14: A bove and left: Magic cut. The two cavities of bicornuate partial uterus bind near cervix. Above and right: Septum uterus image with 3D Doppler angiography shows vascularization present in the septum. Never present in the separation of the two horns in cases bicornis. Bottom: Full bicornuate uterus. TUI

Magic cut mode by performing a perfect delineation of both horns show the partial or total nature of the malformation, showed in the image at the bottom (Fig. 14).

In bicornuate uterus, Doppler angiography fails to show vascularization in the central area, since the two cavities are separated. Figure 14 shows a septate uterus with central vascularization which helps for differential diagnosis.

\section{Group V: Septate Uterus}

It is the result of the reabsorption failure of the septum and may be partial $(\mathrm{Vb})$ or complete (Va). Septate uterus is the most common Müllerian malformation.

Using 3D US can be differentiate septate versus bicornuate uterus. ${ }^{22-24} \mathrm{~A}$ careful evaluation of the uterine fundus is preceptive. Septate uteri show a flat or lineal fundus, whereas bicornuate shows a typical indentation (Fig. 15).

This type is the most common Müllerian malformation, twice as much as bicornuate uterus. The sub-septate variant $(\mathrm{Vb})$ is present in $85 \%$ of cases.

Herein, we show a set of complete septum images (type Va), the septum reaching cervix and vagina (Figs 15 to 18$)$.

Complete septate uterus: Note, in the frontal plane, the lineal uterine fundus (yellow line) and the septum reaching the external os (yellow arrows). To the right: $3 \mathrm{D}$ view using 'magic cut' software, the septum is signaled (red arrow).

Complete septate uterus with two cervix (yellow arrows): To the left TUI mode. To the right 3D magic cut.
Septate uterus with partition wall in cervix and vagina. Top left and center, and 4D images HDLive. The right image is a VOCAL. Bottom left and right TUI, magic cut mode, the 'septum' reaching the cérvix is signaled with a yellow arrows.

Magnetic resonance imaging of a complete septate uterus in a case initially diagnosed as a didelphys uterus. Upper row:3D US image showing the septum, including a septate vagina and cérvix. Bottom row: MRI image depicting two cervical Canals (center) and both vaginas (right).

Now, we show incomplete septate uterus images (type Vb) (Fig. 19).

Four-dimensional (top) and TUI (bottom) images of partial septum uterus in a case initially described as a bicornuate uterus using hysterosalpingography and hysteroscopic procedures. Three-dimensional US clearly shows a sub-septate variant, also one cavity reveals more developed.

To differentiate bicornuate from septate uterus the following criteria are used:

- Perform linear measurement from the tip to tip of the endometrial cavities (red line), which connects the two horns.

- Measure the longitudinal separation between above mentioned linear measurement and the fundus (see green arrow) ${ }^{20}$ (Fig. 20).

If this crosses the fundus or is $<5 \mathrm{~mm}$, the uterus is considered bicornis, while if it is $>5 \mathrm{~mm}$ is considered septate. It is indifferent to the form given to the fundus whether it is straight or with a slight indentation (Fig. 20). 


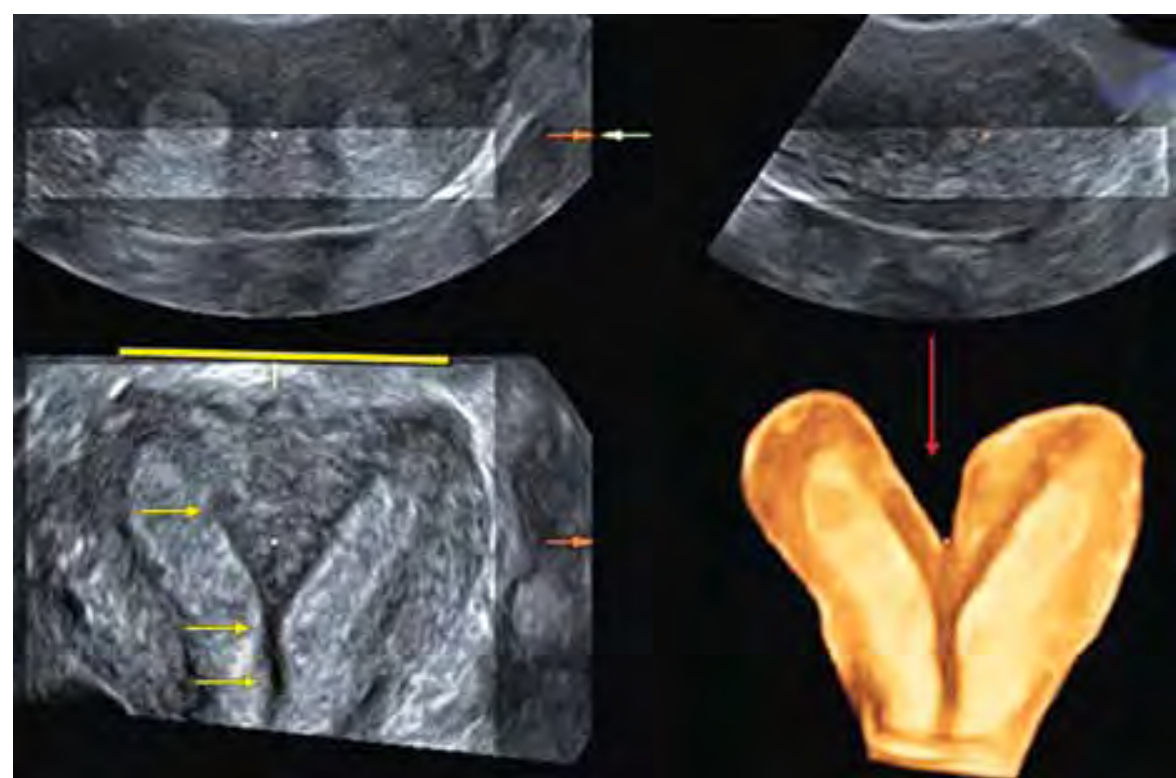

Fig. 15: Complete septate uterus. Note, in the frontal plane, the lineal uterine fundus (yellow line) and the septum reaching the external os (yellow arrows). To the right: 3D view using 'magic cut' software, the septum is signaled (red arrow)
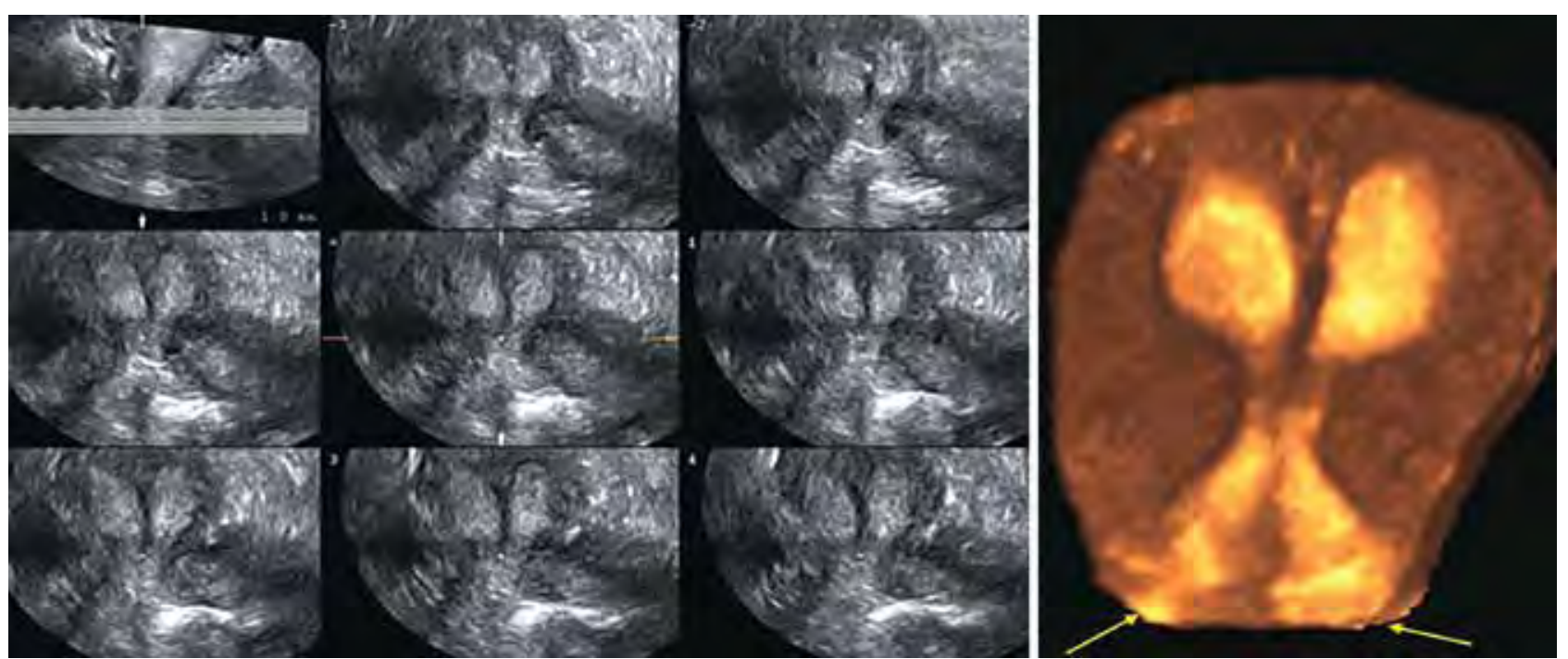

Fig. 16: Complete septate uterus with two cervix (yellow arrows). To the left-TUI mode. To the right-3D magic cut

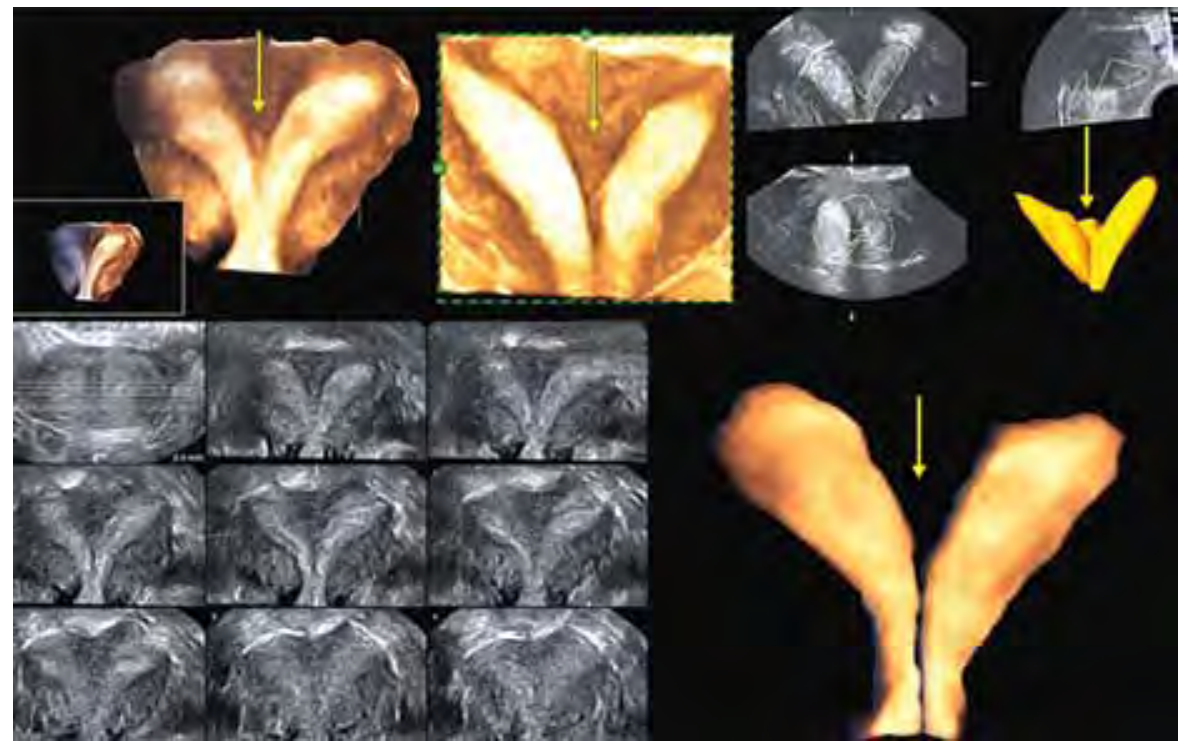

Fig. 17: Septate uterus with partition wall in cervix and vagina. Top left and center, and 4D images HDLive. The right image is a Vocal. Bottom left and right TUI, magic cut mode, the 'septum' reaching the cérvix is signaled with a yellow arrow 


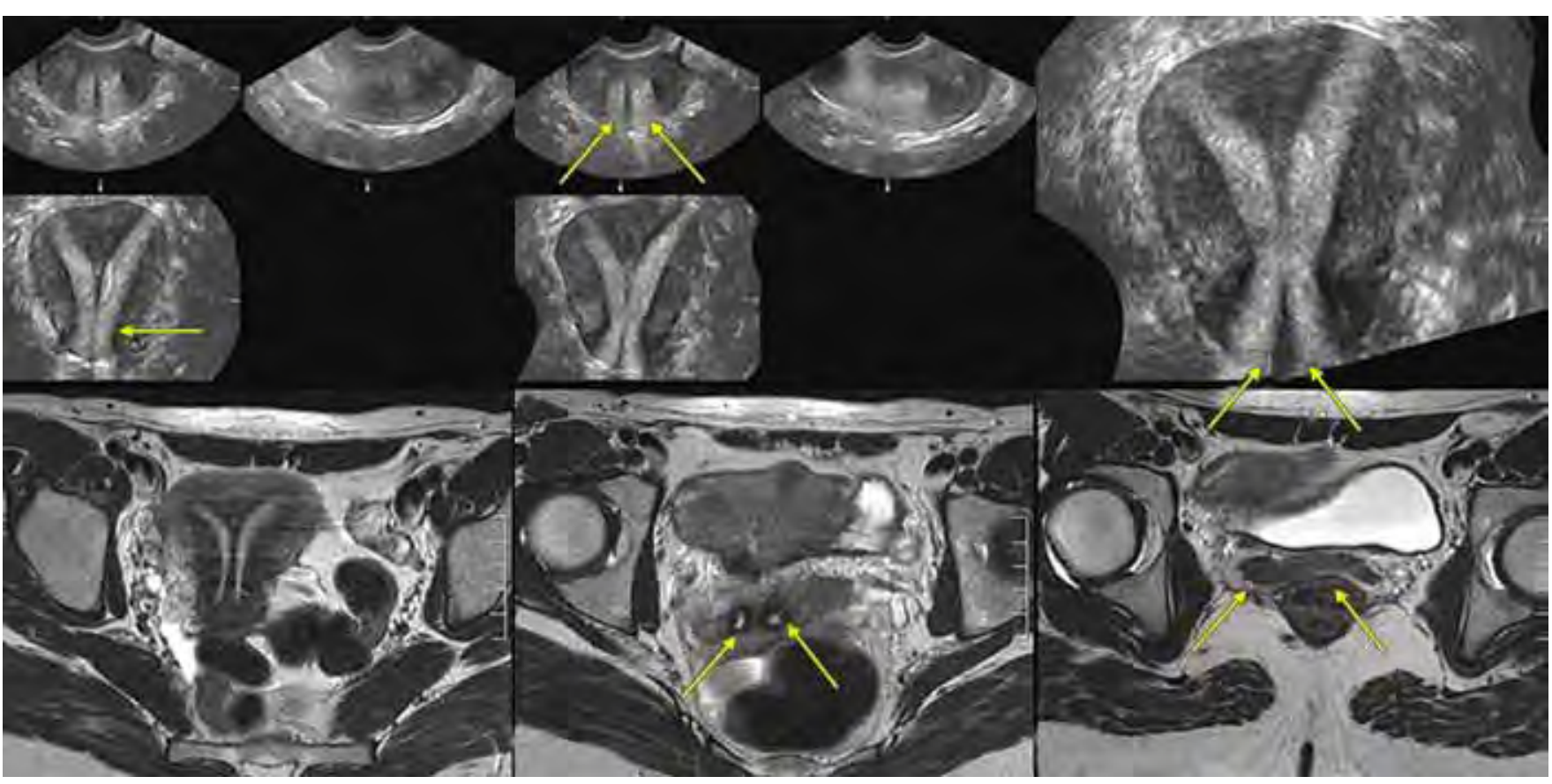

Fig. 18: Magnetic resonance imaging of a complete septate uterus in a case initially diagnosed as a didelphys uterus. Upper row: 3D US image showing the septum, including a septate vagina and cérvix. Bottom row: MRI image depicting two cervical canals (center) and both vaginas (right)

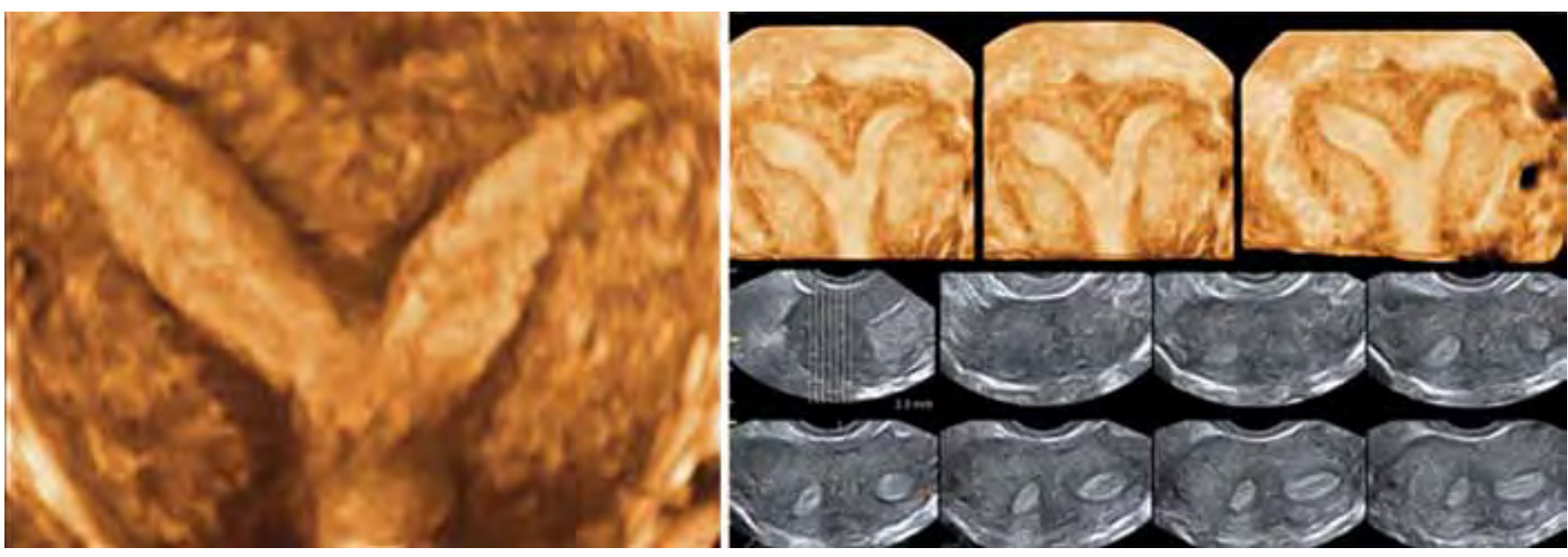

Fig. 19: Four-dimensional (left) and TUI (right) images of partial septum uterus in a case initially described as a bicornuate uterus using hysterosalpingography and hysteroscopic procedures. Three-dimensional US clearly shows a sub-septate variant, also one cavity reveals more developed

Cuando se emplea la RNM todos los casos con una incisión $>1 \mathrm{~cm}$ en el fundus han sido considerados bicornes.

- The visualization and measure of the fundal indentation: The image of fundal slit is important for diagnosis, but it should be more than $10 \mathrm{~mm}$ for the differential diagnosis of septate uterus (Fig. 20).

- Measuring the angle compound between both endometrial cavities: Can be performed both hysterosalpingography (HSG) or 3D vaginal ultrasound in luteal phase, when these are more prominent ${ }^{21-26}$ (Fig. 20).

Considerations regarding the angle between the two endometrial cavities:

- If less than $75^{\circ}$ is considered septate uterus. No more studies are needed.
- If it is $75^{\circ}$ to $105^{\circ}$ the differential diagnosis must be completed by adding ultrasound and hysterosalpingography. Most are sepyate uterus.

- If the divergence angle is greater than $105^{\circ}$ is a bicornuate uterus.

The difference between septate and bicornuate uterus is summarized in Table 2 and Figure 21.

\section{Septa Uterus with Cervical Duplication: A Rare Müllerian Anomaly (Type Va)}

Within the group of septate uterus, there are variants of extreme rarity which also contradict classic embryology:

Figure 22 shows a longitudinal vaginal wall reaching to outer third of the vagina and two independent cervixes. 


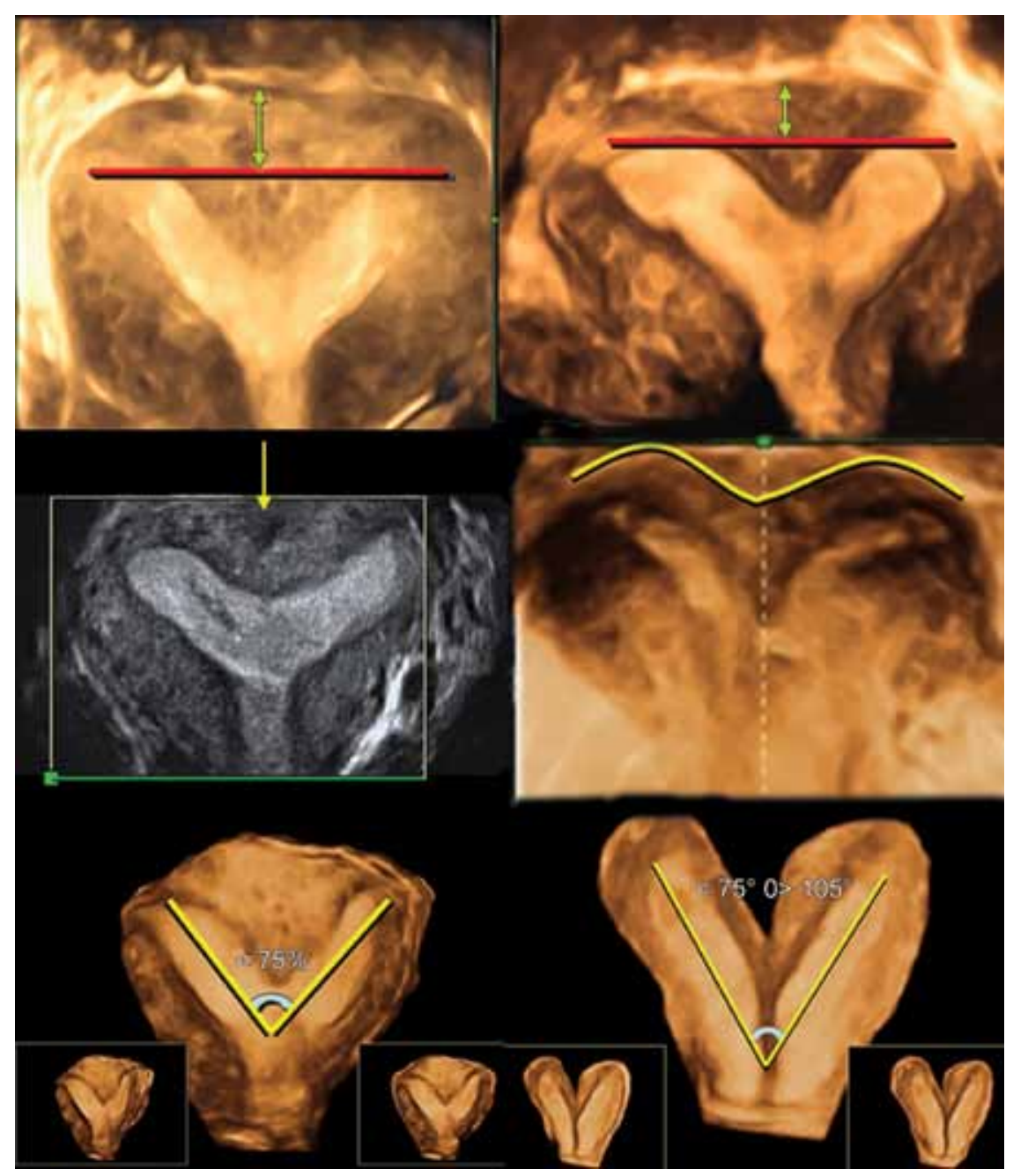

Fig. 20: Top: Partial septate uterus. The fundal line measure is $>5 \mathrm{~mm}$ as described by Troiano et al $2011 .{ }^{20}$ Center: Images show the indentation of a bicornuate uterus, the yellow arrow designates the uterine fundus and the yellow line delimits the fundus bounds. Bottom: Measure of the angle between the two endometrial lines; an angle $<75^{\circ}$ corresponds to septate uteri, whereas angles $>105^{\circ}$ to bicornuate uteri. Angles between 75 and $105^{\circ}$ are inconclusive

The 3D shows a linear fundus with a wall partition that reaches cervix. This is a complete septum associated with uterine cervical and vaginal duplication.

Figure 23 shows a complete septate uterus (red arrows), with cervical duplication (yellow arrows) and vaginal septum. The 3D ultrasound image clearly shows linear fundus with complete uterine septum to OCI (red arrows) and the presence of two separate cervix (yellow arrows).

Müller ducts appear in week 6 to 7 from the coelomic epithelium covering the genital ridge, in the absence of AMH they grow caudally to reach the urogenital sinus, subsequently, between weeks 11 and 13 get jointed, creating a septum that will be reabsorbed.

Classically, it has been argued that the fusion of the Müllerian ducts began in the urogenital tubercle and progress cranially, resulting in a single structure divided by the septum into two symmetrical cavities. Resorption septum would begin in any part of the septum and would progress in both directions (cranially and caudally), the
Table 2: Differential diagnosis between septate and bicornuate uterus

\begin{tabular}{ll}
\hline Septate & Bicornuate \\
\hline Angle $<75^{\circ}$ & Angle $>105^{\circ}$ \\
Linear uterine fundus & Fundus with 'notch' \\
Distance between & Distance between \\
horns $<4 \mathrm{~cm}$ & horns $>4 \mathrm{~cm}$ \\
Distance endometrium-fundus $>$ & Distance endometrium- \\
$5 \mathrm{~mm}$ & fundus $<5 \mathrm{~mm}$ \\
Vessels in septum Yes & Vessels in septum No \\
\hline
\end{tabular}

type of uterus described here, is incongruent with the classical theory, since it is the result of a failed fusion distal scale (double cervix) with subsequent total failure of the septum resorption.

According to McBean and Brumsted ${ }^{87}$ fusion would occur in the middle portion of the paramesonephric conduct and would progress in both directions (both caudal and cranial). This helps to explain this type of uterus as a fusion failure (double cervix) with proper fusing cranial. 


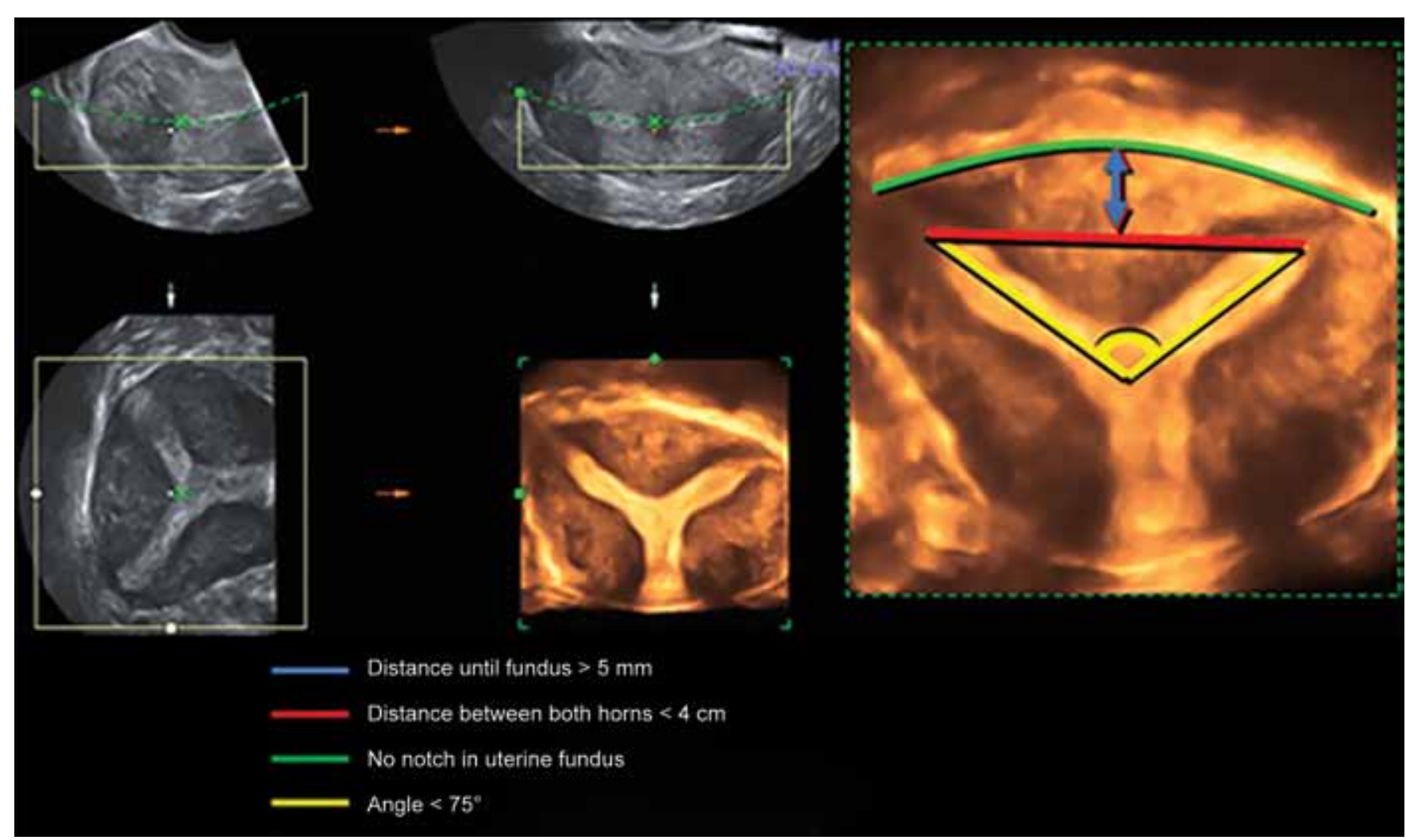

Fig. 21: Sub-septate uterus. Colored lines depict the diagnostic criteria. Yellow: angle between the two endometrial lines. Red: upper endometrial lining. G reen: Outer bounds of the uterine fundus. Blue: Distance from the endometrial lining to the uterine fundus
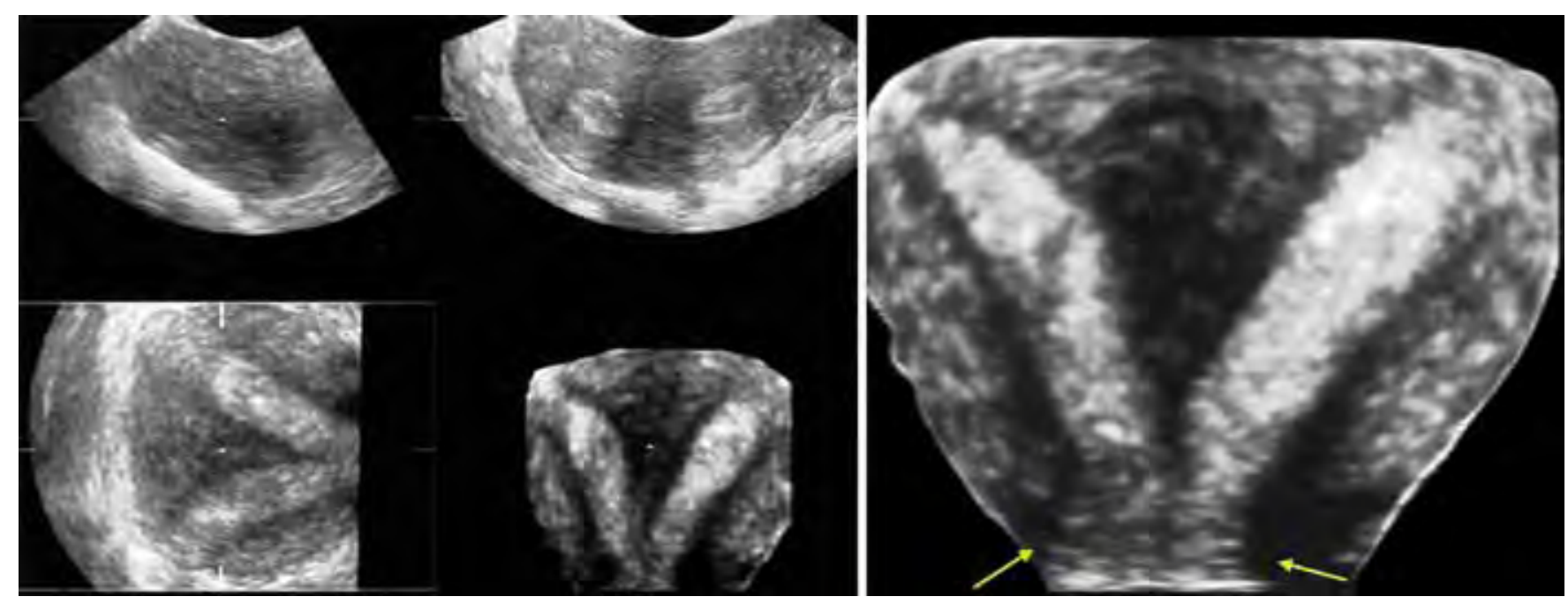

Fig. 22: Complete septate uterus. Yellow arrows show the presence of the septum in the cervical canal

Such failures can not be included in the AFS classification since this only supports the presence of a double cervix in cases of uterus didelphys and bicornuate.

\section{Group VI: Arquate Uterus}

Represents a minor anomaly, caused by the failure of terminal fusion of the Müllerian ducts. Initially, it was considered a variety of uterine septum. The ASRM classification labeled it an own group, given its clinical features, totally different from the mentioned uterus.
It is considered a variant of normality, as it is not associated with an increased incidence of obstetric and reproductive disorders. But today has generated much controversy, as some would be associated to bad reproductive prognosis (Figs 24 and 25).

Three-dimensional shows a linear fundus with an arched shape endometrial cavity (Figs 24 and 25).

Medical literature, ${ }^{25-28}$ describes that this variety and the uterine hypoplasia represents two thirds of all uterine anomalies. 


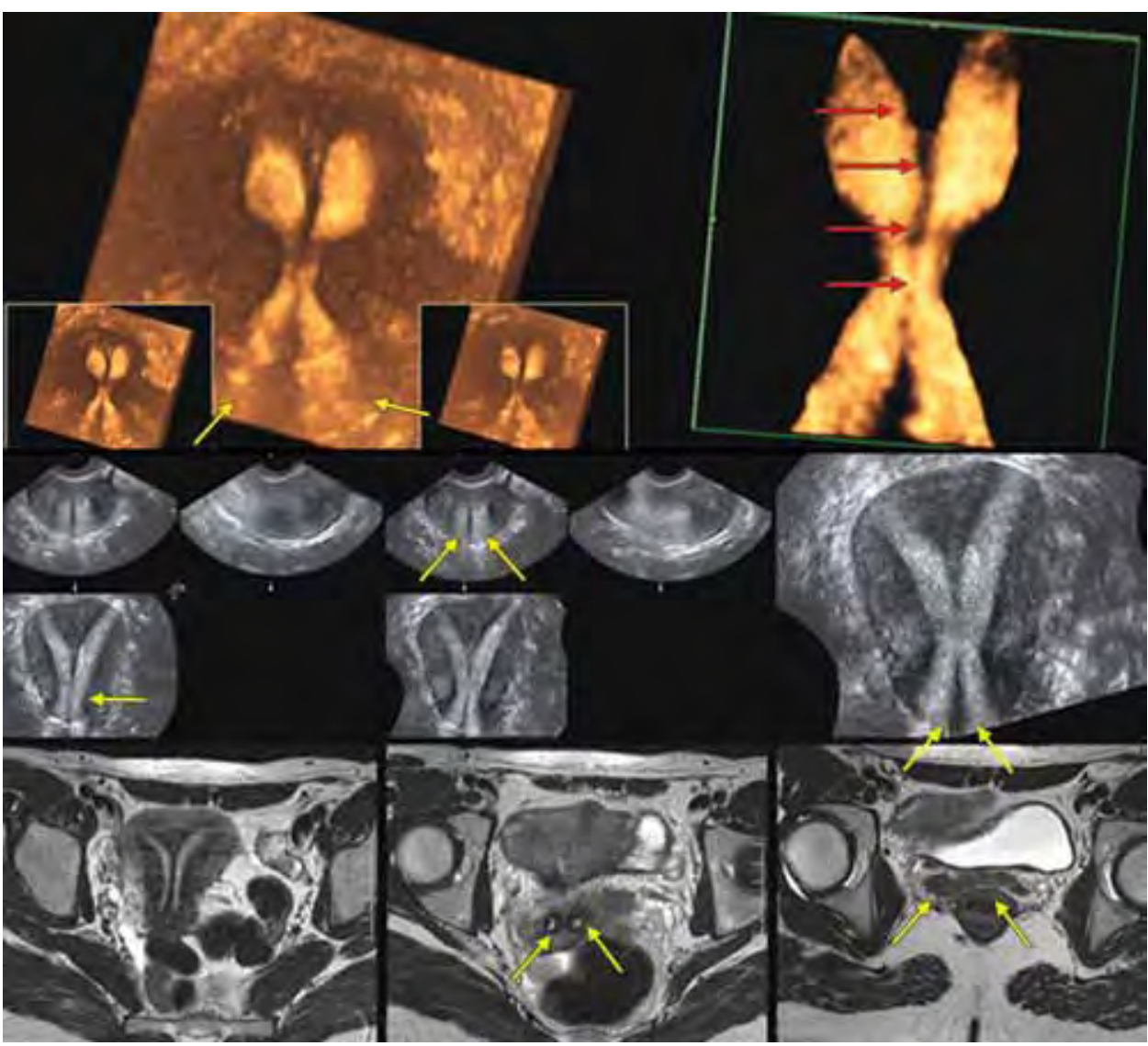

Fig. 23: Top: Complete septate uterus (red arrows), double cérvix (yellow arrows) and vaginal septation. Bottom: 3D US and MRI of the same case
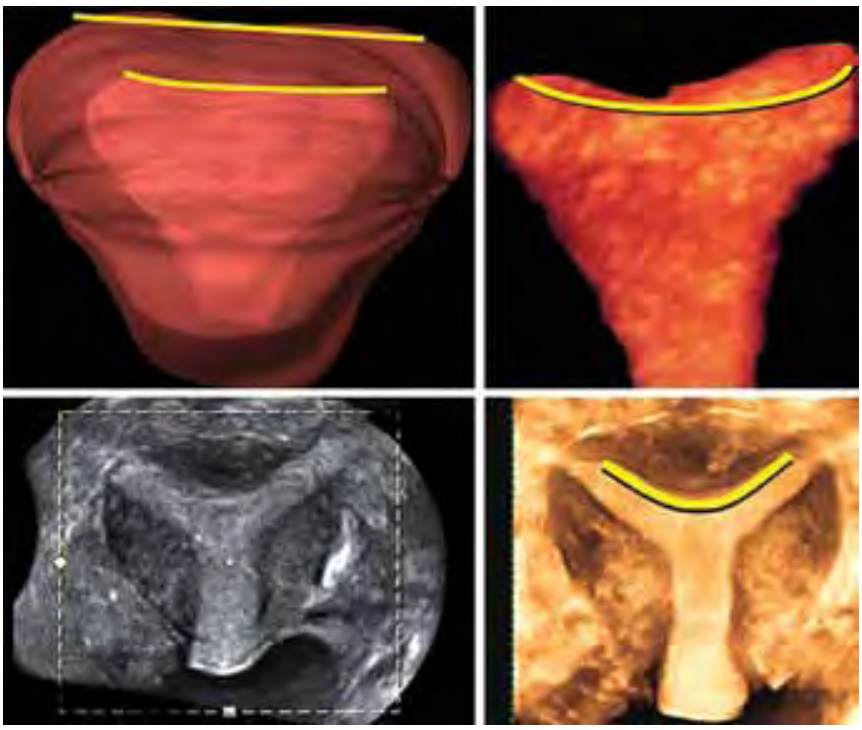

Fig. 24: Arcuate uterus. Top left: Vocal system. Top right: 3D US using magic cut. Bottom left: Coronal plane. Bottom right: 3D US. Yellow lines depict the endometrial and uterine bounds

\section{Group VII: Related with Dietilestilbestrol Uterus}

Nonsteroidal estrogen DES was used in the management of various obstetric complications, including first trimester bleeding, recurrent miscarriage, pre-eclampsia, premature delivery, etc.
The first alarm was given in 1970, as it relates to the appearance of clear cell carcinomas of the vagina of adolescents exposed in utero. A year later, the FDA banned its administration during pregnancy. Sadly, some year later, the association between intrauterine exposure and Müllerian anomalies was also described. The ASRM included it as a subtype in its Müllerian malformation classification system.

This type of uterus typically shows a $\mathrm{T}$ shape morphology of the uterine cavity, as a consequence of the uterine constriction produced by hypertrophy of the myometrium adjacent to atrophic areas. Hypotrophic uterus, vaginal adenosis and cervical abnormalities are also usually described in this type of Müllerian malformation.

The use of DES was prohibited many years ago; our group have never encountered a single case of this rare Müllerian malformation. Very few cases are described in medical literature. ${ }^{29,32}$

\section{MÜLLERIAN MALFORMATIONS NOT INCLUDED IN THE AFS CLASSIFICATION}

\section{Communicans Uteri}

Although they are known since many years ago, they are very rare. This group is formed by uteri with independent cavities wich are communicated in a particular point. 


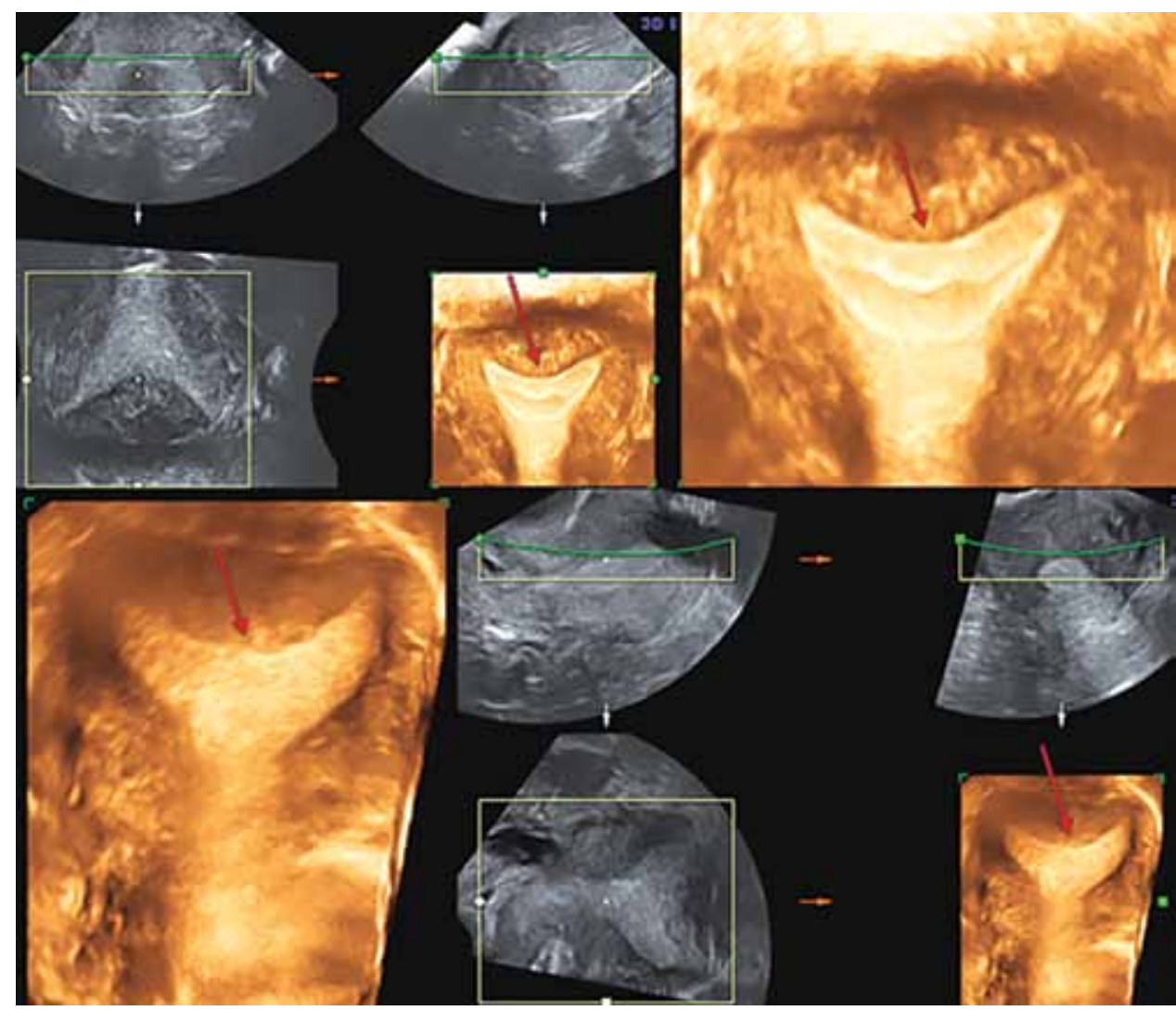

Fig. 25: Two cases of arcuate uterus. The characteristic is the arched shape of the fundus we have indicated with red arrows. With 3D we can see the arched shape. With 2D can be confused with a septate uterus

In 1922 Hadden $^{30}$ described the first case and since then, different varieties have been described and agrupated by Toaff ${ }^{31}$ in the only classification of this type of uteri (Fig. 26).

\section{Origin}

They result from abnormal embriological development of the uterus. ${ }^{31}$

During 10th week of gestation, the caudal portion of Müllerian ducts take contact in the middle line. During 11th and 13th weeks, these ducts fusionate, forming the middle septum. During 13th and 20th weeks, this septum regresses. ${ }^{32}$

We show here with 3D ultrasound, AVC and Vocal our most recent case of this type of uterus (Fig. 27).

\section{EMBRYOLOGY AND CLINICAL MANIFESTATIONS}

Very little is known about how the resorption of the uterine septum is made. Embryologists just tell us that the resorption of the septum begins in the 9th week and when the 11th week is reached, the resorption is completed. They do not tell us nothing about the mechanism of this resorption, nothing about the anomalies that may arise resulting from this process.

The fussion of the Müllerian ducts occurs at 22 weeks of gestation, reaching both fused ducts the backside of the urogenital sinus. After this, Müllerian ducts complete their fussion from the caudal to the cranial aspect of the uterovaginal canal, finishing this process with the septum resorption.

Depending on the fussion (complete or incomplete), the result is a single organ or a uterus with two horns on its external conformation. The teratogenic cause that prevents the continued resorption of the septum (that had already started) should not act on the fusion of the Müllerian ducts, probably because as stated above, communication between uterus is present not only in septated uteri (without fusion failure), but also in bicornuate uteri (with fusion failure).

The noxa that causes this anomalie should act only during the fetal period of development and for a short time, between weeks 9 and 11, according to the Carnegie Institute of Washington.

Toaff ${ }^{31}$ has pointed out different ways of communicating uteri (Fig. 30), distinguishing two groups:

- Alteration of the fusion, types II, IV and V

- Without alteration of the fusion, types I and III

We think that the first type is hardly admissible as the author draws it because (as happens in the fourth one), there is not a vaginal septum. In fact, there are not two cervix, but only one with two separated holes.

These lesions are associated not only with a unique external conformation of the uterus, but also with a double one. This external conformation can not be demons- 


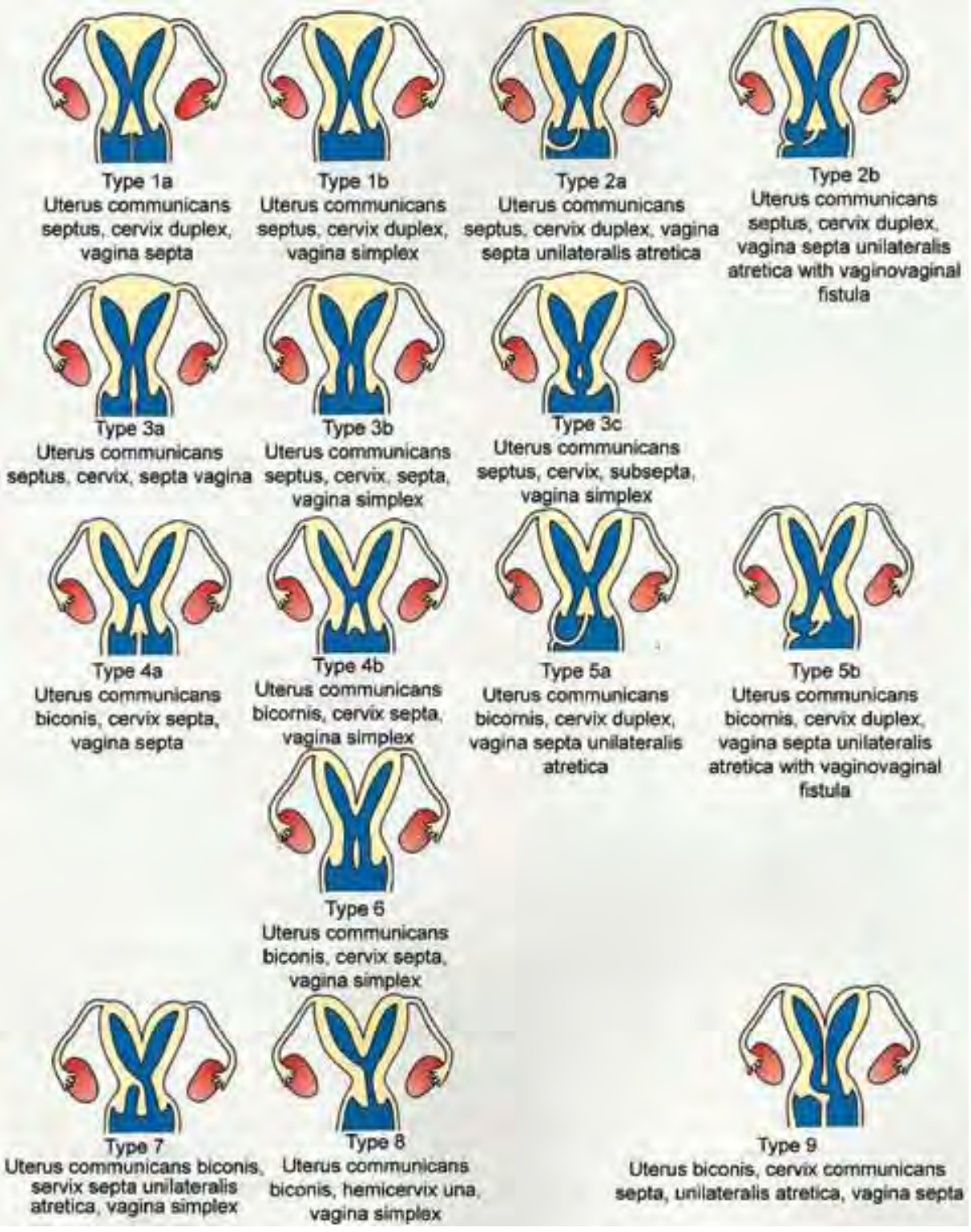

Fig. 26: Toaff classification of communicans uteri ${ }^{31}$

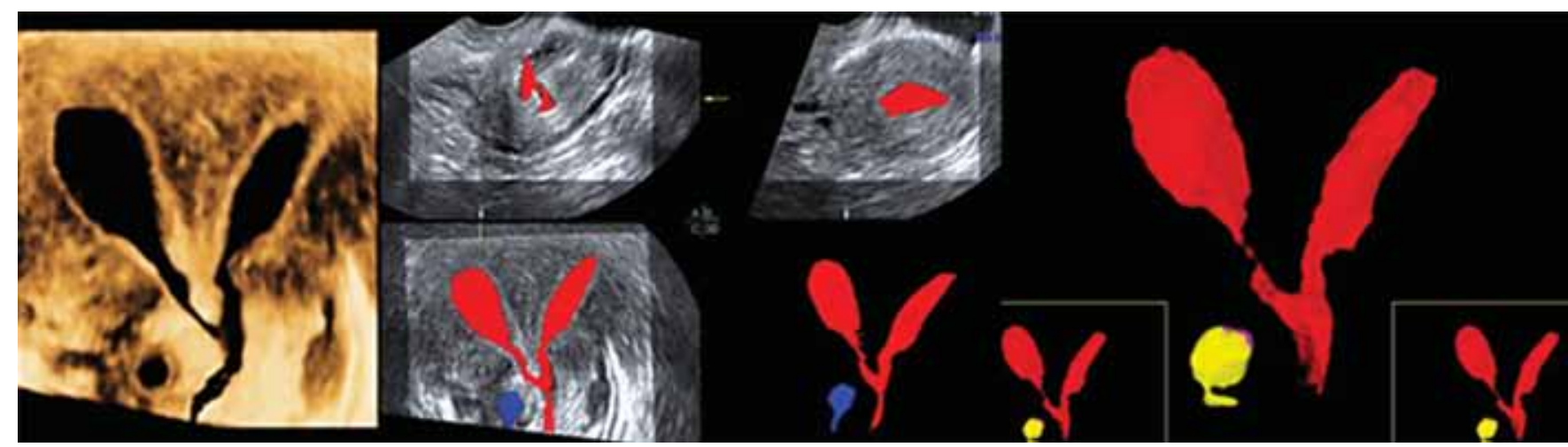

Fig. 27: Communicans uterus. On the left, 3D ultrasound. On the right and in the middle, Vocal mode

trated by the clinician, unless a direct view (laparotomy, laparoscopy) is made. A radiographic examination (gynecological pneumopelvigrafy) could be made as well in order to determine this external conformation without doing an operation.
Besides this, all communicating bicornuate uteri with septated vagina (type V) do not have urinary tract on the side where the genital pathology is present. The Wolffian duct sited on the side of the blind vagina (stage 11) reaches and punches the sewer, forming the ureteric 
bud (stages 12 and 13). It remains active during the time in which the Müllerian duct is formed and then descends and fuses with the Müllerian duct on the other side (stages 16-22). If this does not happen, the Müllerian duct will not continue its development, staying in the same point in which the Wolffian duct stops.

\section{How the Kidney and Ureter on this Side Disappear?}

Metanephros is induced by the ureteric bud of the corresponding side (stages 13-14) to form the kidney. After this, the same teratogenic noxa (perhaps anoxia) that causes genital anomalies also cancels the development of the urinary system from that side. It would not be a renal aplasia, but the disappearance of the kidney that was formed in the embryonic stage of development.

With regard to vaginal pathology in these cases, there are two uterine horns and two vaginas (one blind) because Müllerian ducts do not undergo a correct fusion. Thereby, at stage 23 its relationship with Müller's tubercle is independent of the tubes.

The formation of a double vagina would be related to the formation of two vaginal plates in week 11. This plaque progresses caudally to the end of the urorectal septum (week 17). Cavitation of this vaginal plate starts in week 19 and is completed in week 20, so this vaginal pathology (double vagina and one of them blind) must have occurred at advanced ages (after week 11). Because of that, with regard to the embryogenesis of this blind vagina, two explanations can be accepted:

- Vaginal plaque caudal progression stops, so only a short portion from the urorectal septum is occupied by the cellular component of the vaginal plate (this happens between weeks 11 and 17). When the vagina is then cavitated, this cavitation would happen only where cellular elements of the vaginal plaque are.

- Vaginal plaque caudal progression continues to the end of urorectal septum (week 16) but when cavitation occurs at later times (weeks 19-20) it only affects the cranial portion of the vagina, not the caudal one.

Definetely, if the resorption of the septum begins in the 23th embryonic period and ends in the embryo of $56 \mathrm{~mm}$ (10 and a half week), it is difficult to understand how this association occurs between communicating uterus and vaginal malformation, since the vagina is formed in the 11th week. Perhaps, dates for different events in human development must undergo some modification in the future.

\section{UTERI BIFORIS UNICORPOREUS}

They have a single uterine body but two cervixes separated by a vaginal septum. They are extremely rare.
They can present themselves in three different ways:

a. Asymmetric duplication of the portio

b. Symmetric duplication of the portio: Two cervix, usually hypoplastic, separated by a better or worse developed vaginal septum and accompanying large fusion anomalies of Müllerian ducts: didelphys uterus bicornis bicollis, etc. In all cases there is a vaginal septum.

c. Duplication of the cervical canal: A unique portio with a septum that divides the cervical canal into two halves. The case we show belongs to the second group.

\section{HYPOPLASTIC UTERI, INFANTILE UTERI AND ATAVISTIC UTERI}

They are smaller than the other ones:

- In the HSG and 3D/4D US endometrial fundus is T-shaped o has a cup form (Figs 28A to F).

As said before, these infantile and hypoplastic uteri have very large and narrow cervix, characteristic of the moment they stopped in their embryologic development. $^{33}$

- MEAKER index: Ratio of the size of uterine body and cervix less than 0.60 . This ratio varies throughout life. By week 24 it is set in 0.13 , then it increases to an average value of 0.38 at the end of pregnancy, and finally it increases by hormonal effect throughout life ( 0.75 is the normal value). Values lower than 0.60 are characteristic of hypoplastic uteri, while values lower than 0.25 are typical from infantile uteri ${ }^{33}$ (Figs 29 and 30)

- When the uterus measured by ultrasound is:

- From the cervix to the endometrial fundus the large is smaller than $6 \mathrm{~cm}$.

- Or from the cervix to the uterine body fundus the large is smaller than 6, $5 \mathrm{~cm}$ (Fig. 30).

\section{Atavistic Uteri}

A star shaped cavity with two asymetric horns.

\section{Infantile Uteri}

Slow or bad development of the uterus due to a lack hormone action during fetal and adult life. They are related to seterility and infertility problems (Figs 28A to F). All these varieties are included today in the DES group of the American classification, having an ominous reproductive prognosis.

\section{NEW PROPOSAL OF CLASSIFICATION}

Different classifications of the female genital tract congenital malformations have been proposed for their categorization, but all of them have serious limations 

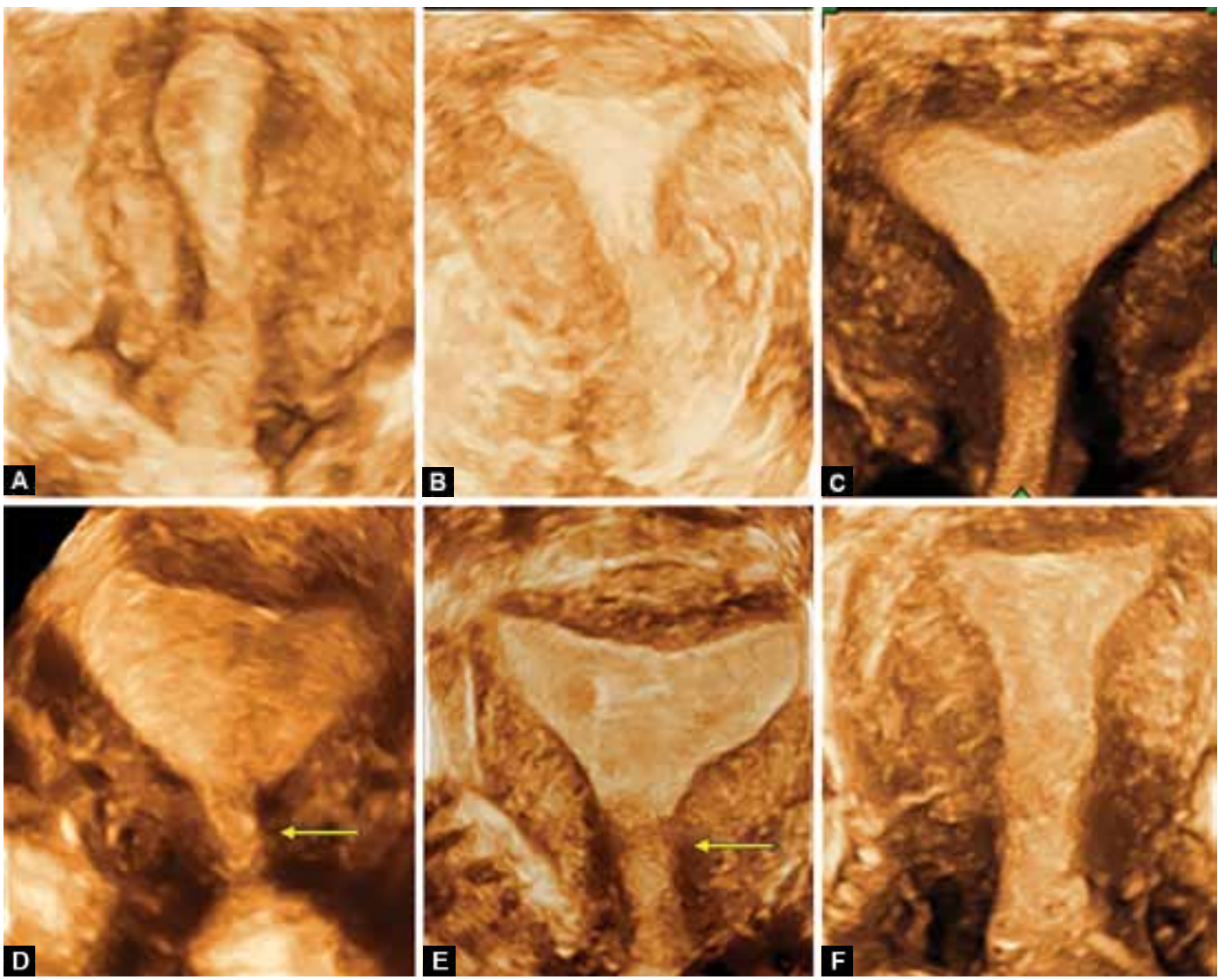

Figs 28A to F: (A) Hypoplastic uterus: plate endometrium, thin and light (top and left) (B) atavistic: both uterus and endometrium are very small (top and center), ( $C$ to $E$ ) cup form: the uterus is like a 'trophy athletics cup'. They show as well a very typical narrow cervical canal, (F) Infantile uterus (bottom right), small dimension. The relationship cervix/uterus body is one and cervical canal is dilatated, sharing both of them (cervical canal and body the same thickness)

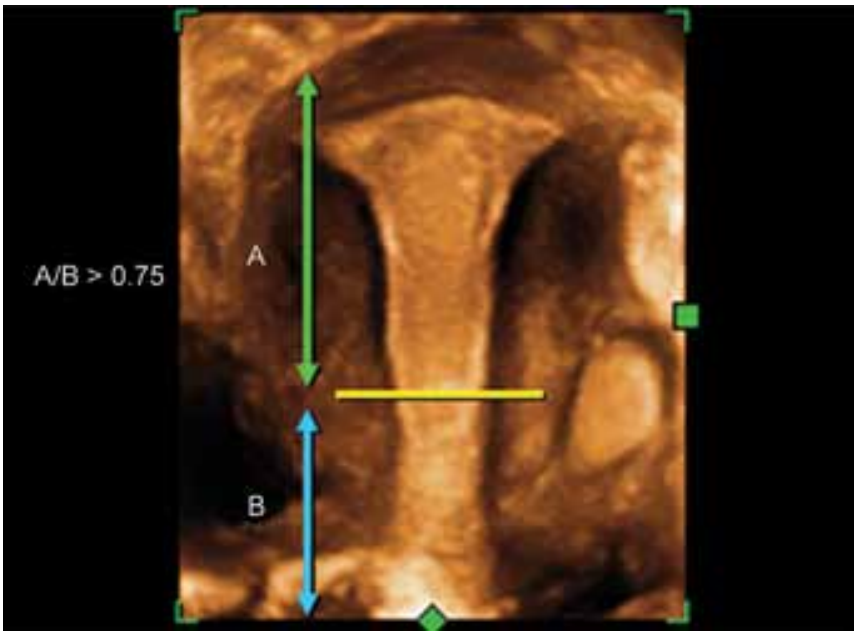

Fig. 29: Meaker index: $A / B \geq 0.75$

because neither of them integrate all the possible deviatons from the normal anatomy.

Recently, Acién ${ }^{1}$ has proposed a new classification that includes the lowest genital anomalies, so instead of calling them Müllerian malformations he calls them genital ones. He consideres that genital tract malformations must include those ones that affect the development and morphology of fallopian tubes, uterus, vagina and vulva,

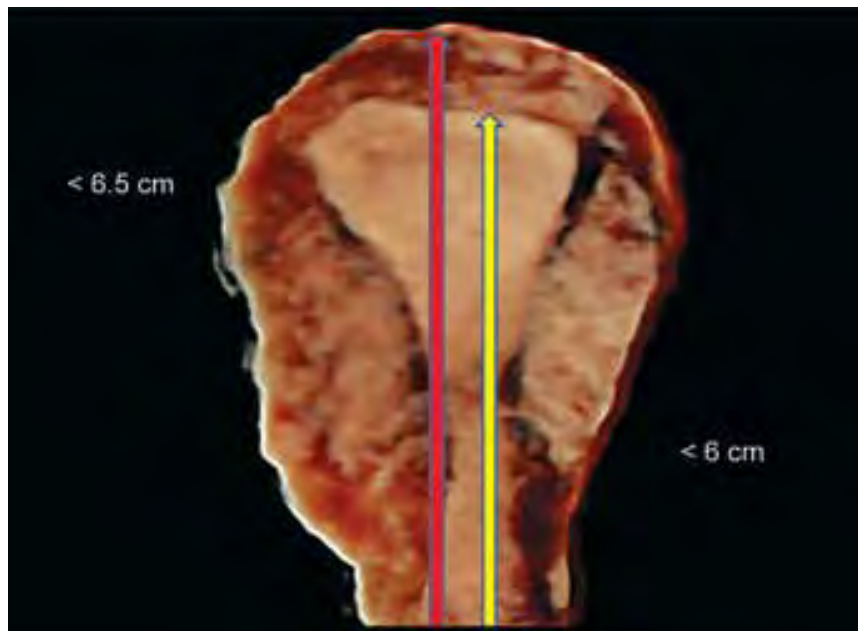

Fig. 30: Uterine measure by abdominal transvaginal ultrasound. Yellow and red lines show how measures have to be done

with or without associated malformations from ovarios, urinary system or bones.

This concept only excludes alterations from the sexual genotype (chromosomal alterations, male histocompatibility antigen, sexual region from the $\mathrm{Y}$ chromosome and the gene from the testicular determination) and from the sexual differentation (because of abnormal stereidogenesis or pseudohermaphroditism). 
In the second point of this classification, entitled 'Uterine Duplicity', communicans uterus from Toaff ${ }^{31}$ and Bonilla ${ }^{34}$ are included. This classification also includes T-shaped uterus in the third point. The final part of this classification includes anomalies that are not included in the classic classification, such as segmentary anomalies, accessory uterine masses and urogenital sinus abnormalities. ${ }^{1}$

Very recently, a new classification system was recently proposed by ESHRE and ESGE ${ }^{89}$ (Fig. 31).

\section{DIAGNOSIS}

A great variety of techniques have been used in order to diagnose these anomalies. Many of them are antique, but other ones are as prevalent as when they were introduced.

If only the uterine cavity is studied, the HSG and the hysteroscopy are essential. But if we want to see the shape of the uterine fundus, laparoscopy or laparotomy are needed. Among all of them, 3D/4D/HDLive US and magnetic resonance imaging (MRI), both noninvasive, have arised as the greatest diagnosis methods in the last ten years. Magnetic resonance imaging has proved to be an excellent option (it is the gold standard), ${ }^{35-37}$ while $3 \mathrm{D}$ and $4 \mathrm{D}$ US provide very similar images to those ones obtained by MRI. ${ }^{38}$

\section{PELVIC EXAMINATION}

The vaginal speculum examination and bimanual touch offers many limitations except for group I of uterine anomalies. It is possible to diagnose vaginal, cervical or uterine agenesis. Vaginal septum, imperforate hymens and cervical duplication can be diagnosed with a pelvic examination $^{29}$ (Fig. 32).

\section{HYSTEROSALPINGOGRAPHY}

It has a good sensitivity and specificity for the study of the uterine cavity, however, it is less useful in the study of uterine anomalies since it does not provide any information about the external uterine contour, neither about the presence of uncommunicated uterine horns. Consequently, the HSG cannot distinguish between septate uteri and bicornuate uteri because they have very similar appearance when the HSG is done, so the study of the fundus morphology with another method is essential. Despite this, it is still valid.

\section{VIRTUAL HYSTEROSALPINGOGRAPHY}

Recently, virtual HSG has appeared. ${ }^{39-44}$ The technique consists of a traditional HSG obtained by using a

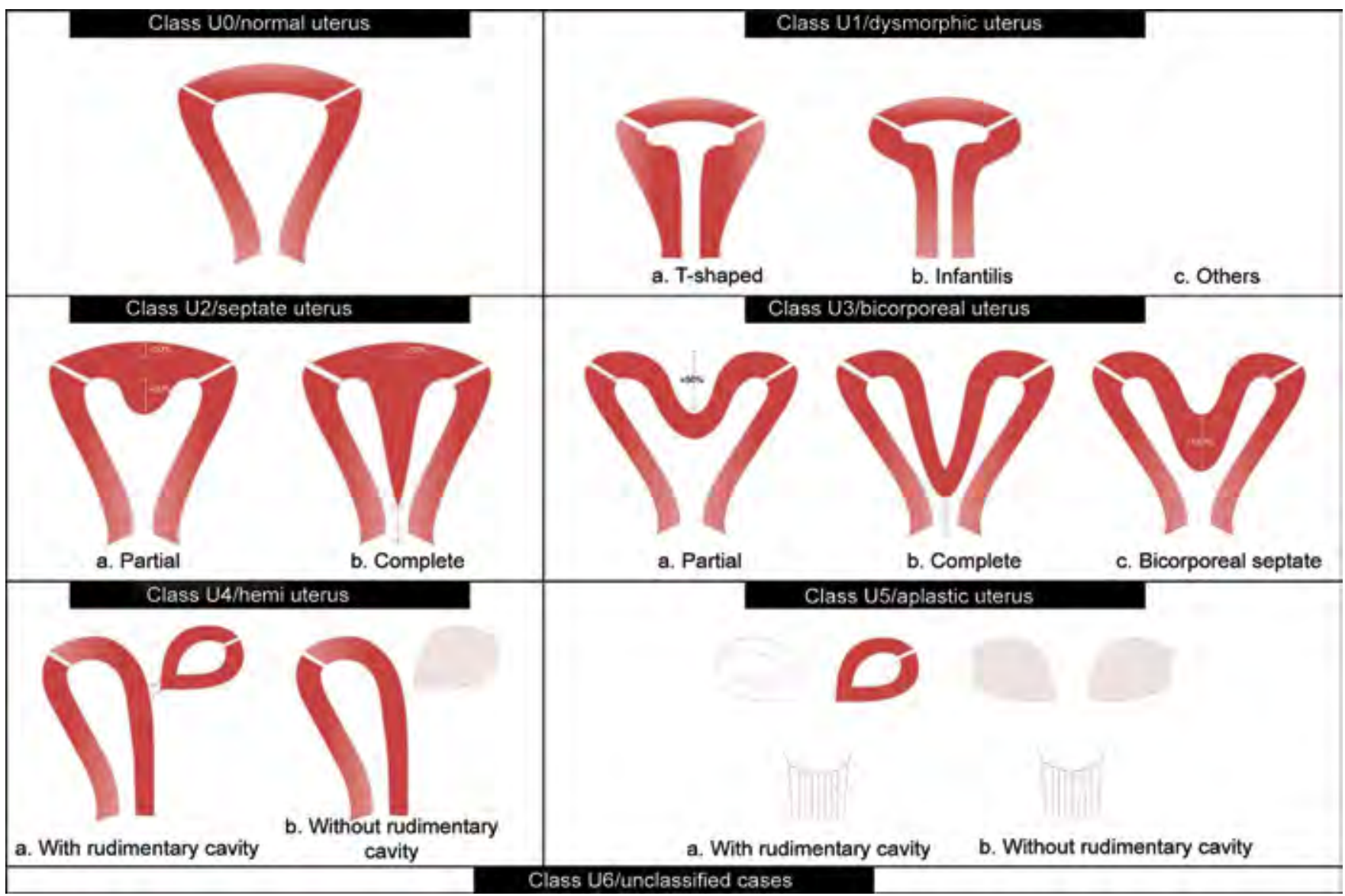

Fig. 31: ESHRE/ESGE classification of uterine anomalies: schematic representation (Class U2: internal indentation $>50 \%$ of the uterine wall thickness \& external contour straight or with indentation $<50 \%$, Class U3: external indentation $>50 \%$ of the uterine wall thickness, Class U3b: width of the fundal indentation at the midline $>150 \%$ of the uterine wall thickness) 


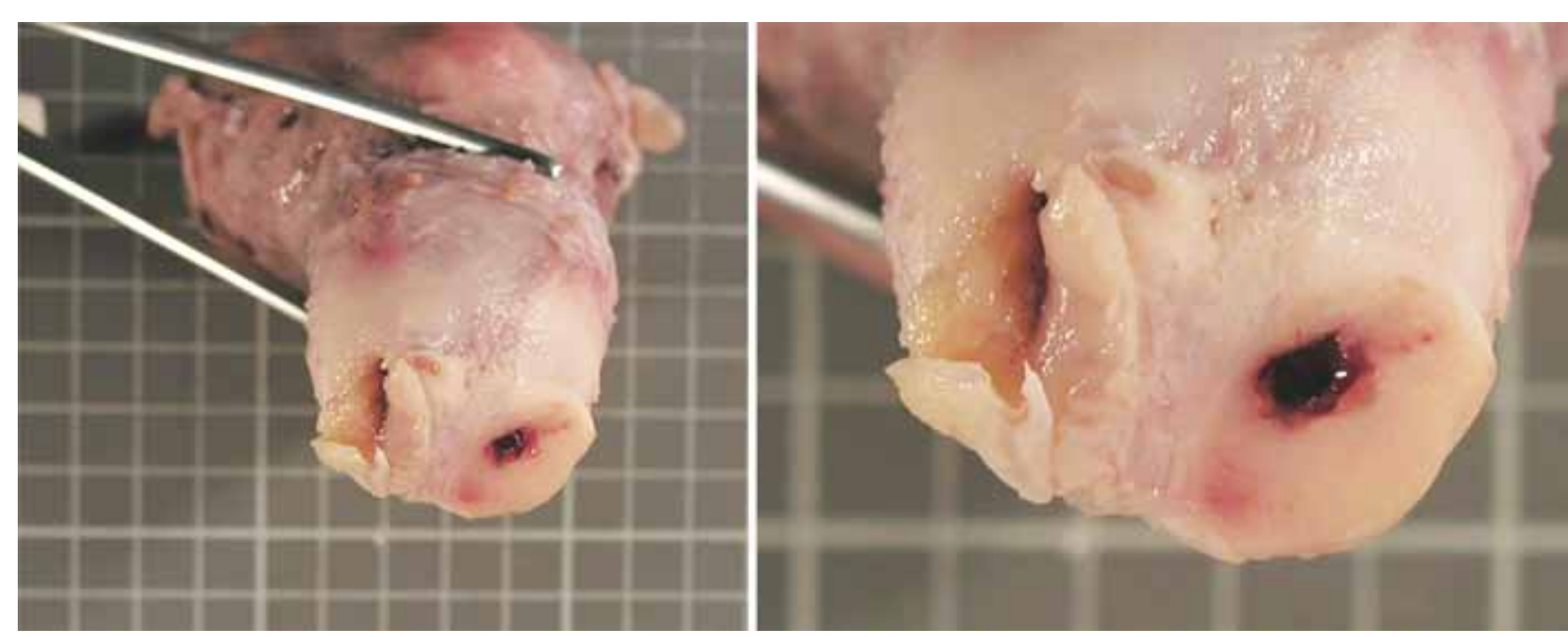

Fig. 32: Double cervix and vaginal septum

multidetector CT technology and making millimeter cuts of the area of interest. After doing this, all the information is processed by a software that performs threedimensional virtual reconstructions. Besides showing uterine cavity and fallopian tubes contours, it also allows to see intrauterine cavity and intrafallopian tubes as if a hysteroscopy has been done. ${ }^{42,43}$

Virtual HSG produces low radiation exposure and it is done in a short time. ${ }^{44}$ It has been applied in the diagnosis of these malformations, particularly in the differential diagnosis of bicornuate uterus and subseptate one ${ }^{43}$ (Fig. 33).

\section{LAPAROSCOPY}

It increases the diagnosis accuracy of HSG, but it is an invasive technique. It is essential to differentiate bicornuate from septate uteri. While bicornuate uteri show a fundal identation, septate uteri do not show it. It identifies rudimentary non-communicating horns, provides information of the pelvic cavity and allows the diagnosis of adhesions and endometriosis.

\section{HYSTEROSCOPY}

As laparoscopy, it is both diagnostic and therapeutic because it can be used not only to diagnose, but also to treat diseases, such as uterine synechiae, polyps, fibroids, etc. It is helpful as well in the treatment of uterine septum. It provides extraordinary information, but it is limited in the evaluation of non-communicating by cervix uterine anomalies.

\section{MAGNETIC RESONANCE IMAGING}

The gold standard in the diagnosis of these type of anomalies. Recent studies have demonstrated a sensitivity of $100 \%$ and specificity of $79 \%$ in the analysis of these uterine anomalies. Prospective studies comparing

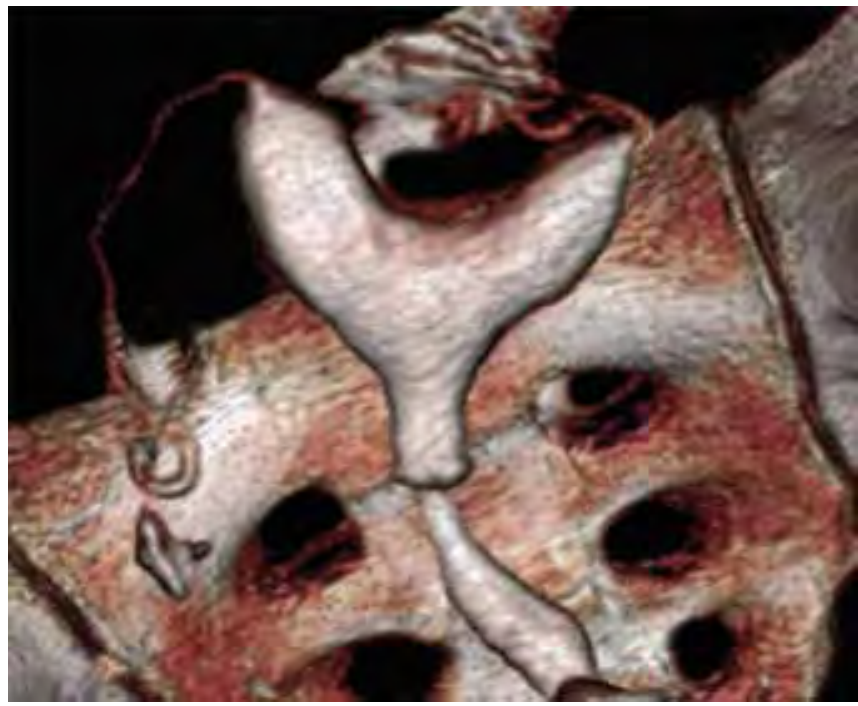

Fig. 33: Cervix, uterus and fallopian tubes (from R ef 39)

HSG, vaginal ultrasound and MRI have shown greater diagnostic reliability on $\mathrm{MRI}^{35-37,45,66}$ (Figs 8, 13 and 18).

\section{ABDOMINAL ULTRASOUND}

It should not be used, because it is antique. It only diagnoses uterine abnormalities in $47 \%$ of cases. ${ }^{46-48}$

\section{TRANSVAGINAL ULTRASOUND}

It presents a sensitivity of $100 \%$ and a specificity of $80 \%$ when studying uterine anomalies. Furthermore, it identifies cases which need a laparotomy or hysteroscopy with the $100 \%$ of sensibility and specifity. ${ }^{36}$

\section{TRANSVAGINAL DOPPLER COLOR}

It permits the study of uterine vascularization and vascular flow from uterine septum, allowing the differential diagnosis between septate and bicornuate uteri (which no present vascularization between hemiuteri). 
A recent study has reported that the vascularization of the septum is related to reproductive prognosis. When greater the vascularization is, the incidence of obstetric problems increases. $^{49-52}$

\section{HYSTEROSONOG RAPHY/HYSTEROSALPINGO- SONOGRAPHY}

It consists of the introduction of a water-soluble contrast (physiological saline) into the cavity, so when the contrast distends the cavity, any anomaly can be seen. The drawback is the limited information we get from the fundus, but this can be overcame by combining 3D US with contrast $(15,53-5515$ see also later 84$)$ (Fig. 34).

\section{THREE-DIMENSIONAL TRANSVAGINAL ULTRASOUND}

Transvaginal 3D shows great sensitivity and specificity in Müllerian anomalies and also in the study of uterine contour. $^{56-62}$

Its great advances are:

- Frontal view of the uterus, impossible to achieve with $2 \mathrm{D}$ vaginal US and essential for the diagnosis of malformations.

- Ortogonal planes allow to see in the same image 3 spacial planes.

- Vocal mode (Virtual semi automatic organ calculatión). It allows semi-automatic volumetric calculation while providing spectacular images (Figs 6, 7 and 17).

- Magic scissors cutting mode. It removes not wanted sonographic areas, leaving only the image of the organ we are studying (Figs 14, 15 and 17)

- TUI mode. Similar to a MRI, performs serial images of any structure you want to study, separated only by few millimeters (Figs 7, 14 and 16).
- HDLive mode. It sends a light beam to the virtual 'region of interest', resulting in improvement of the image quality by combining light and shadow (Fig. 10).

Recently, this technology has been applied to yield new diagnostic criteria of uterine septum. ${ }^{63,64}$ HDLive US were used to determine the width, length and surface area of uterine septums by using hysterosonography in order to predict anatomic results after complete hysteroscopic metroplasty (Figs 35A to C). Significant predictors of anatomical results were the septum width.

In conclusion, with 3D transvaginal ultrasound we obtain images in seconds without requiring contrast media radiopaque, without radiating. HDLive is ambulatory and does not require specific menstrual days, it is not painful and shows the front view of the uterus and all uterine layers. It allows as well 3D vision of normal and pathological morphology of the vagina, cervix, uterus, tubes and ovaries $^{56-60}$ and it is cheaper than other techniques.

\section{HOW TO MAKE THREE-DIMENSIONAL ULTRASOUND}

\section{Examination of the Uterine Cavity and Cervical Canal}

The problem with this type of US is to see together the uterine cavity and cervix. So transducer must be separated slightly from the portio to the vagina so that the cervix is displayed (Fig. 36).

- The initial plane to obtain 3D volume is generated on a midsagittal cut (top and left). From there, 3D develops orthogonal planes through an angle of $90^{\circ}$. The plane $\mathrm{B}$ (top right) is the axial plane and the $\mathrm{C}$ (below and left) is the coronal one. The 3D box is then set on the

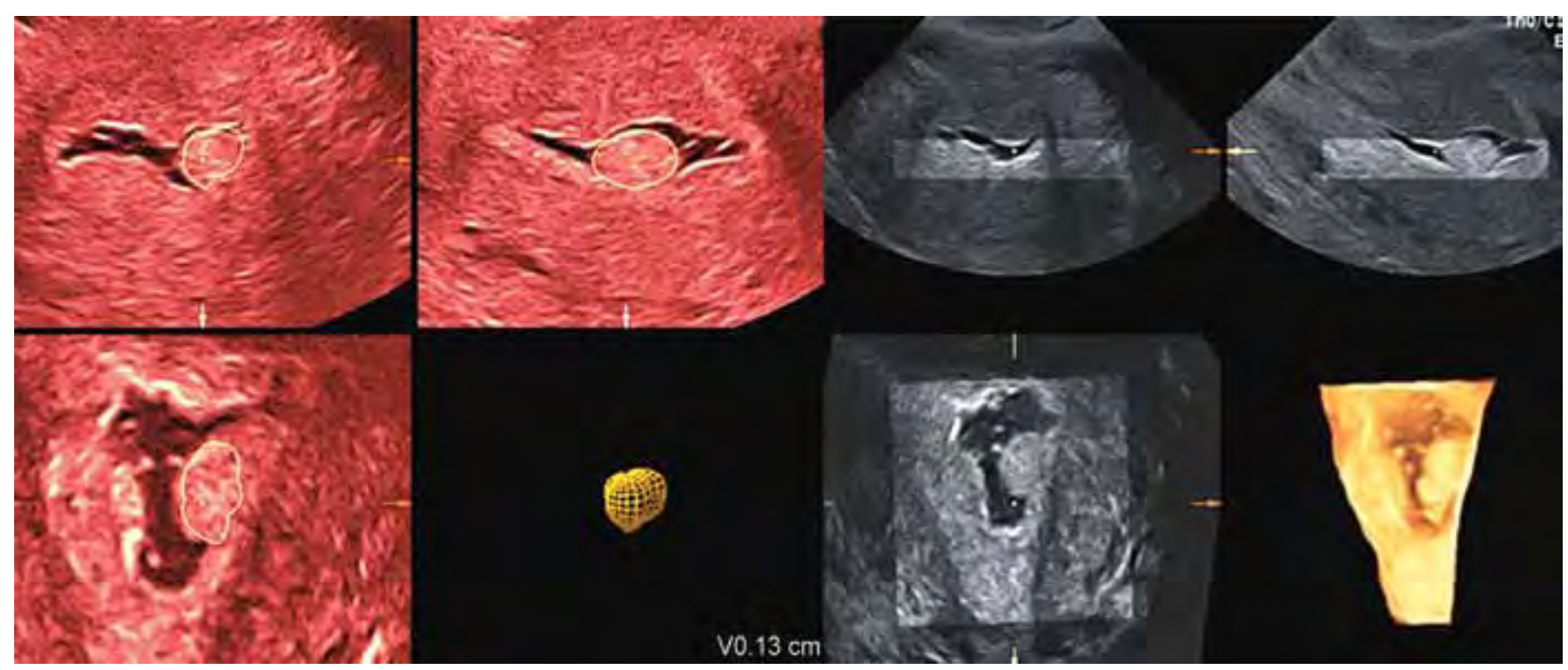

Fig. 34: Three-dimensional and 4D HSG from the endometrium. Normal cavity distended with saline, showing a polyp. Vocal used to measure polyp volume. This technique is rarely used despite its interest 

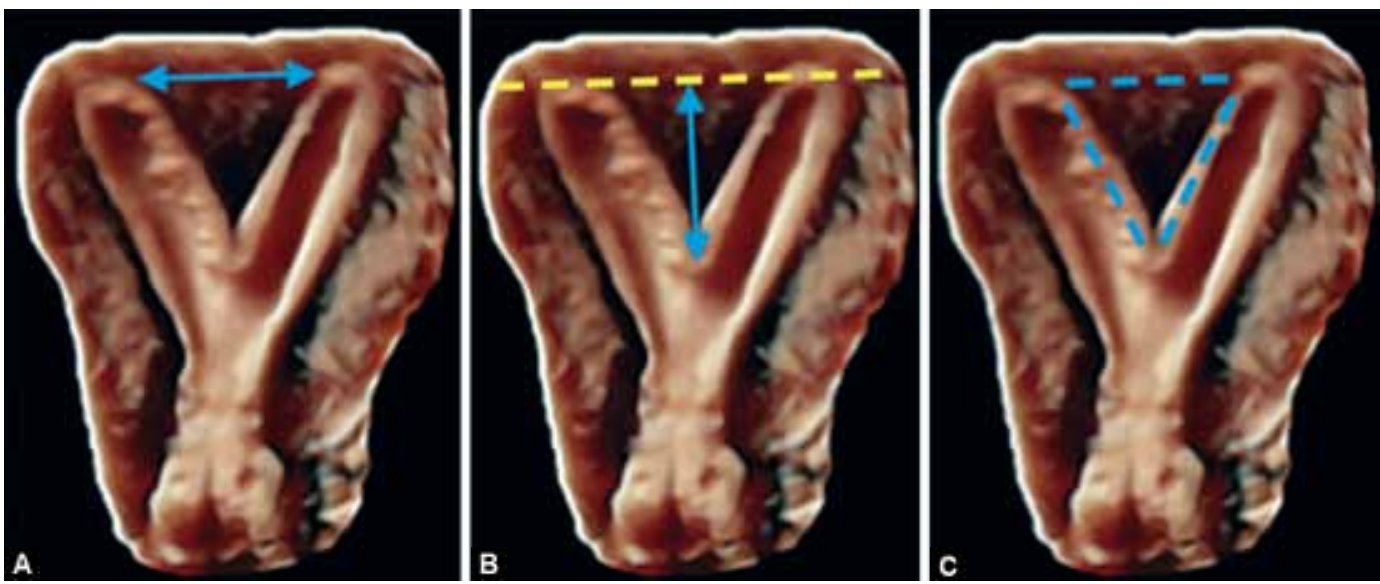

Figs 35A to C: HDLive of a septum in order to see uterine cavity prior to surgery. Taken from Ludwin. Width in (A), length in (B) and surface area in (C)

plane A so that the green line, which marks the area where the sonic beam enters, is adapted tothe uterine cavity and positioned over the center of the endometrium. Doing this, the best 3D viewing of the endometrium and myometrium is obtained.

- This way of doing the 3D US only varies when the anomaly has a large transverse diameter. The volume is obtained in a transverse plane, so that both uterine horns can be visualized in order to achieve a better estimation of the ratio cavity/fundus in 3D reconstruction.

- In order to study cervix and upper vagina, vaginal transducer is removed from CEO (cervical external os), performing ultrasound sections (Figs 16 and 37$){ }^{65}$

\section{USE OF MRI}

Recent medical evidence supports the use of MRI in addition to 3D US especially for complex uterine malformations. ${ }^{66}$ Our group has used this combination of diagnostic methods in 112 complex mullerian abnormalities.

\section{COMPARING THE SAFETY IN THE DIAGNOSIS BETWEEN 3D US, HSG AND MRI}

To determine the sensibility of the techniques, we have used Zohav criteria (2011), ${ }^{81}$ which compare 3D US with HSG and/or 2D and other techniques (hysteroscopy/ laparoscopy/MRI).

\section{Agenesis}

All our cases are Rokitanski-Küster-Mayer-Hauser syndromes. The diagnosis was based only in the amenorrhea and clinical examination. Abdominal 2D ultrasound confirmed the diagnosis. The most interesting fact is that both abdominal 2D and 3D US confirmed the presence of rudimentary uterus (100\%) (which was observed with MRI).

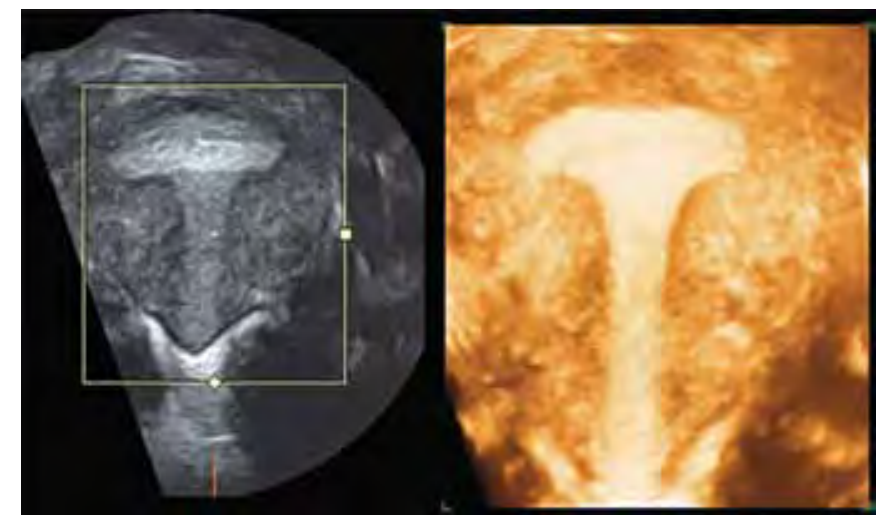

Fig. 36: Procedure for obtaining 3D images in cases of Müllerian anomalies. This case is a hypoplastic and T-shaped uterus, with a long cervix. The examination is first done with 2D US with a midsagittal cut, adjusting the capture window so that an optimal $3 \mathrm{D}$ volume is obtained. This ROI window is adjusted from fundus to cervix (see image above and left, green line shows where the sound beam enters). At this point the 3D volume is obtained by doing a scan of $90^{\circ}$
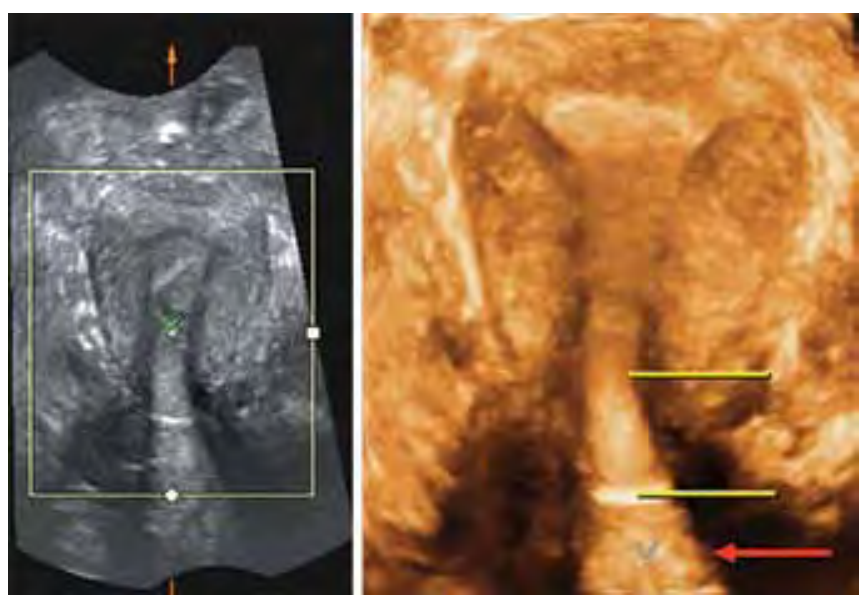

Fig. 37: Three-dimensional image of cervix and vagina. The orthogonal plane shows how the sound beam enters in the vagina. Full uterus, endometrium, cervix whole (yellow lines) and vagina ( $\mathrm{V}$, red arrow) are showed

\section{Unicornuate Uteri}

The coincidence was $93 \%$ for 3D with hysteroscopy and $100 \%$ with MRI. 


\section{Didelphus Uteri}

Clinical examination showed the vaginal septum and two cervices. The coincidence between 2D US/3D US/ Laparoscopy/MRI was $100 \%$.

\section{Septate Uteri}

The 3D ultrasound confirmed $84.3 \%$ of them. The hysteroscopic study changed to $75 \%$ ( 24 cases) cases of septated uteri and increased to 8 on the bicornuate uteri (25\%). Magnetic resonance imaging confirmed $90.6 \%$ of septated uteri and only $9.3 \%$ of bicornuate uteri.

\section{Arquate Uteri}

A lot of disagreement is found in this group. From 60 cases diagnosed by 2D/3D US, only 20 (33\%) were confirmed by 3D US. $62.7 \%$ were normal uteri while two uteri were considered as subseptated (3.3\%). The hysteroscopic diagnosis is even more definitive, as only $16.5 \%$ were labeled as arcuate uteri and the two cases viewed by 3D US were confirmed.

\section{Normal F indings with 2D/HSG}

It is a very interesting group. All cases were normal with the HSG and 2D US. Normal uteri were confirmed with 3D US in $61,2 \%$ of cases, while one of them was diagnosed as unicornuate (3.2\%) and the rest (35.4\%) were arcuate.

Attached tables show how these techniques correlate with each other.

Three-dimensional US confirms the initial diagnosis made by 2D US/HSG in almost 80 to $100 \%$ of cases of severe Müllerian malformations: agenesis are diagnosed in $100 \%$ of cases; unicornuate uteri in $78 \%$ of cases; didelphys in $100 \%$; septate uteri in $84 \%$; cervical duplication in $100 \%$; biforis communicating unicorporeus in $100 \%$.

The most important disagreement occurs when the bicornuate uteri, arcaute uteri and hypoplastic uteri are diagnosed. In fact, 3D US only confirms bicornuate uteri in $26 \%$ of cases, arcuate uteri in $20 \%$ and hypoplastic uteri in $33 \%$.

Of greater significance is the 3D compared with hysteroscopy. Hysteroscopy confirms $73 \%$ of the unicornuate uteri and $100 \%$ of the didelphys. Significant differences are as expected for arcuate uteri (16.7\%) and less for the septate uteri (75\%).

The most interesting comparative study is established with MRI, but unfortunately it is only carried out in 112 of cases: in 53\% of cases, 3D US agrees in 100\% of cases of agenesis, unicornuate uterus, didelphys, arcuate, cervical duplication and biforis. It agrees in $90 \%$ of cases of septate uteri and in $75 \%$ of communicans.
In conclusion, 3D ultrasound is a very good technique for the diagnosis, as good as MRI is and better than 2D US and HSG.

\section{DISCUSSION}

In most uterine malformations, especially the less extreme forms (arcuate uteri, subseptate uteri and incomplete bicornuate uteri) only two uterine endometrial cavities are seen with 2D vaginal US.

However, with 3D US is very evident the relationship between the uterine cavity and the fundus, allowing an accurate diagnosis because of the contribution of the C plane (or coronal), which does not exist with the 2D US. It is a very important plane in the diagnosis of these malformations. . $^{29,65}$

To distinguish these small anomalies is important not only because of their different reproductive prognosis, but also because of different ways and techniques of treatment.

Three-dimensional US allows measurements such as the length and thickness of the septum (see differences between septate and bicornuate uteri described) and the gap between the two endometrium. It also calculates volumes (AVC and Vocal) and studies its vascularization, ${ }^{52,67-70}$ all of which can affect the reproductive prognosis. $^{25,26,71,72}$

\section{STUDIES WITH 3D US}

First publications with 3D US were made in obstetricsgynecology fields. They showed the technology to produce images of fetal faces with a very poor quality and isolated cases of uteri with Müllerian or tumor pathologies. ${ }^{21,73,74}$ It is from the first half of the 90s when very interesting publications, almost all descriptive ${ }^{23,24,56-60,67-70,72,75-78}$ appear, and they have been compared with other techniques, particularly with magnetic resonance imaging. $29,38,79-82$

Exceptional cases have been described (communicating uteri) ${ }^{29,76}$ and very recently some others affecting cervix and vagina. ${ }^{65}$

Accurate diagnosis in uterine malformations with 3D US is known for years. Jurkovic et al $1995^{75}$ compared 2D and 3D US with HSG, finding that both ultrasound modalities were not only more efficient in the diagnosis of arcuate uterus, but also that both had a high predictive value in large anomalies, especially in the differentiation of bicornuate uteri and septate uteri. The 3D US far exceeded the limitations of 2D and HSG because of the coronal plane of the uterus it provides.

In 1996, Raga and collaborators showed that 3D US had a safety index of $91.6 \%$ when evaluating the uteri 
fundus, and a safety of the $100 \%$ when studying the uterine cavity when compared with laparoscopy and HSG. ${ }^{67-69}$

In 1997, Wu et $\mathrm{al}^{23}$ found that 3D US had a safety index of $92 \%$ in the diagnosis of septate uteri and of $100 \%$ in the bicornuate ones when comparing with laparoscopy and hysteroscopy.

In 2005, Alcázar et $\mathrm{al}^{77}$ and other studies ${ }^{80}$ which compared 3D US with endoscopy, revealed a sensitivity of 97 to $100 \%$, specificity of 96 to $100 \%$, positive predictive value of $92 \%$ and negative predictive value of $99 \%$ with $96 \%$ concordance between US and endoscopy, depending on the type of undiagnosed abnormality.

In 2007, Mohamed et al $^{79}$ compared 3D US with hysterocopy and laparoscopy, obtaining a sensitivity of $97 \%$, specificity of $96 \%$, positive predictive value of $92 \%$ and a negative predictive value of $99 \%$. When specifying the type of malformation, these indices would be up to $92 \%$ in the diagnosis of septate uteri and $100 \%$ for bicornuate uteri.

While Ghi et $\mathrm{al}^{80}$ obtained indices of sensitivity and specificity of $100 \%$ and a $96 \%$ of agreement between ultrasound and endoscopy related with the different types of the anomalies diagnosed. The 3D diagnostic value would be similar to the MRI one.

When compared with 3D US, 2D US IS a sensitive method for diagnosing Müllerian malformations, ${ }^{23,35,47,62}$ but it only provides a limited view of the uterine fundus and therefore it can not really differentiate between arquate, bicornuate and septate. ${ }^{35,47,48,85}$

Hysterosalpingography provides information of the contour of the uterine cavity and tubal pathology, but it is not only unable to classify different subtypes of congenital uterine anomalies, but also it radiates. ${ }^{86}$

Moreover, hysteroscopy is the standard diagnostic technique in the study of abnormalities of the uterine cavity and may help in revealing suspected or missed by HSG or 2D US septum. ${ }^{29}$

The coronal view allows to study the endometrial cavity and the uterine fundus, thus providing the necessary information to determine the nature and extent of injury.

In the Israeli study ${ }^{81}$ when cases of Müllerian malformations were suspected with HSG and 2D, 3D ultrasound confirmed them in $52.9 \%$ of cases. In all cases a clear vision and good images of the uterine cavity were obtained.

The higher concordance between $3 \mathrm{D}$ results and the initial 2D and HSG was in cases of septate uteri (83\% agreement), while in unicornuate, bicornuate and arcuate ones, concordance rates were 80, 75 and 30.4\%, respectively. In patients with normal HSG and 2D US müllerian anomaly suspected, 3D revealed that these existed in $69.2 \%$. In 14 patients in whom hysteroscopy was performed, the results comparing hysteroscopy with 3D US revealed total agreement (100\%).

The study ends indicating that their results support other studies, including ours, showing that 3D should be part of the diagnosis of congenital uterine anomalies. Besides, 3D volumes can be stored on disk and re-examined as many times as necessary, which facilitates independent verification of diagnoses. ${ }^{67-69,75,79}$

In conclusion, these israelite authors, say that $3 \mathrm{D}$ US is an excellent and safe technology that can be considered as the gold standard in the diagnosis of Müllerian defects. ${ }^{67-69,75,79}$

A Spanish group ${ }^{29}$ has published one of the most important works in Müllerian malformations diagnosed by $3 \mathrm{D}$ US, because of the beauty of the images showed and the comparison with MRI results.

This study reports that in less extreme ways (arcuate uteri, septate, bicornuate) 2D US shows two cavities and few other details. However, using 3D US, the relationship between the fundus and the uterine cavity is evident, what allows an accurate diagnosis because of the contribution of the plane $\mathrm{C}$ (coronal). The distinction between these extreme cases is very important because of their different prognosis and treatment.

Further, it also highlights ${ }^{29}$ the importance of 3D US not only in measuring length and thickness of the septum, but also calculating the volume of uterine cavity and studying the vascularization that can affect fertility prognosis. In the comparative study done with MRI, it reports that the images obtained are practically equivalent, ${ }^{29}$ in fact, the relationship between the fundus and the uterine cavity can be set perfectly with both ultrasound reconstruction in the coronal plane or coronal sequences obtained with MRI.

While the diagnostic accuracy was similar for both techniques, agreeing in classifying anomalies in the AFS classification, interesting was the few observed differences obtained when the malformation was located in the cervix. In order to avoid this, the transducer has to be moved out to study the cervical canal, in order to see if two cervices are present or if a complete or incomplete septum along the cervical canal is. The presence of two channels, generally thick, that diverge in their lower portion, seem to be a double cervix, however, the confirmation can be achieved by examining with the speculum.

Magnetic resonance imaging distinguishes between a septum (although septum contains myometrium at its upper portion) and the cervical myometrium by the different intensity they provide. In terms of intensity, myometrium is the reference, while a weak signal indicates fibrous tissue, and the same signal indicates muscle. 
Magnetic resonance imaging can also differentiate vaginal septum, as these give a less intense signal because of the vaginal wall. This differentiation can not be achieved by using 2D or 3D US, so is necessary to confirm the diagnosis to use the bimanual touch and the speculum. If the bimanual examination is performed routinely in conjunction with the $3 \mathrm{D}$, the results show that both have comparable indices of efficacy/safety. The study gives greater advantages to 3D than to the MRI, because it is cheaper and better tolerated.

Alcázar ${ }^{77}$ confirms this, but his study mentions the sparse diagnostic value in uterus didelphys and indicates that the differential diagnosis between these three varieties (arcuate, bicornuate, septate) is not always easy for both 3D and for MRI. It is based on recognizing the existence of intermediate forms and/or incomplete septum and bicornes, due to simultaneous failure of fusion and resorption of Müllerian ducts.

For example, septate uteri with broad septum have a large distance between the two horns, and the ultrasound septum structure is similar to that of the myometrium. In these cases, the morphology of the cavity and the type of signal obtained from the septum with the MRI, indicating the presence of myometrium (which is theoretically only present in the wall of the bicornuate uteri) allow to obtain an incorrect diagnosis of bicornuate uterus. ${ }^{88}$

Alcázar uses the Troiano and McCarthy formula ${ }^{20}$ in order to distinguish between these two types, what allows to obtain correct diagnosis, specially for septate uteri.

Bermejo $^{29}$ says that he had difficulties in his study in differentiating some intermediate forms of malformations. He did not know where classified them, within the group V or VI, as some very deep arcuate uteri could be partial septum with a short, thick one.

He says that the very marked arcuate uteri would have a worse prognosis than those reproductive malformations involving the cavity not so much, as already mentioned by Troiano and Salim. ${ }^{20,26}$

Bermejo expresses his deep admiration for 3D. In fact, it would be a very useful addition to the 2D US in the field of uterine malformations. He proposes, as we do, that when a Müllerian malformation is detected, 3D US accompanied by a gynecological examination must be done. In cases of doubt or complex malformations, MRI must be used, particularly if cervix and/or vagina is studied.

\section{REFERENCES}

1. Acién P, Acién MI. The history of female genital tract malformation classifications and proposal of an updated system. Hum Reprod Update 2011;17:693-705.
2. Simón C, Martínez L, Pardo F, Tortajada M, Pellicer A. Müllerian defects in women with normal reproductive outcome. Fertil Steril 1991;56:1192-1193.

3. Raga F, Bauset C, Remohi J, Bonilla-Musoles F, Simón C, Pellicer A. Reproductive impact of congenital Müllerian anomalies. Hum Reprod 1997;12:2277-2281.

4. Acien P. Incidence of Müllerian defects in fertile and infertile women. Hum Reprod 1997;12:1372-1376.

5. Buttram VC, Gibbons WE. Müllerian anomalies: A proposed classification and analysis of 744 cases. Fertil Steril 1979; 32:40-46.

6. Acién P. Reproductive performance of women with uterine malformations. Hum Reprod 1993;8:122-126.

7. Acién P. Shall we operate on Müllerian defects? lncidence of Müllerian defects in fertile and infertile women. Hum Reprod 1997;12:1372-1375.

8. Stampe Sorensen S. Estimated prevalence of Müllerian duct anomalies. Acta Obstet Gynecol Scand 1988;67:441-445.

9. Ashton D, Amin HK, Richart RM, Neuwirth RS. The incidence of asymptomatic uterine anomalies in women undergoing transcervical tubal sterilization. Obstet Gynecol 1988;72:28-30.

10. Byrne J, Nussbaum-Blask A, Taylor WS, Rubin A, Hill M, O'Donnell R, Shulman S. Prevalence of Müllerian duct anomalies detected at ultrasound. Am J Med Genet 2000;94: 9-12.

11. Braun $P$, Vercher F, Mut R, Perez D. Is hysterosalpingography able to diagnose all uterine malformations correctly? A retrospective study. Europ J Radiol 2005;53:274-279.

12. Stray-Pedersen B, Stray-Pedersen S. Etiologic factors and subsequent reproductive performance in 195 couples with a prior history of habitual abortion. Am J Obstet Gynecol 1984; 148:140-146.

13. Makino T, Hara T, Oka C, Toyoshima K, Sugi T, Iwasaki K, Umeuchi M, Iizuka R. Survey of 1120 Japanese women with a history of recurrent spontaneous abortions. Eur J Obstet Gynecol Reprod Biol 1992;44:123-130.

14. Clifford K, Rai R, Watson H, Reagan L. An informative protocol for the investigation of recurrent miscarriage: preliminary experience of 500 consecutive cases. Human Reprod 1994;9:1328-1332.

15. Tur-Kaspa I, Gal M, Hartman M, Hartman J, Hartman A. A prospective evaluation of uterine abnormalities by saline infusion sonography (SIS) in 1009 women with infertility or abnormal uterine bleeding. Fertil Steril 2006;86:1731-1735.

16. Saravelos $\mathrm{SH}$, Cocksedge KA, Li TC. Prevalence and diagnosis of congenital uterine anomalies in woman with reproductive failure: a critical appraisal. Human Reprod update 2008;14: 415-429.

17. Jones HW. Reproductive impairment and the malformated uterus. Fertil Steril 1981;36:137-141.

18. Buttram VC. Müllerian anomalies and their management. Fertil Steril 1983;40:159-163.

19. The American Fertility Society classification of adnexal adhesions, distal tubal obstruction, tubal occlusion secondary to tubal ligation, tubal pregnancies. Müllerian anomalies, and intrauterine adhesions. Fertil Steril 1988;49:944-947.

20. Troiano R, McCarthy S. Müllerian duct anomalies: imaging and clinical issues. Radiology 2004;233:19-34.

21. Reuter KL, Daly DC, Cohen SM. Septate versus bicornuate uteri: errors in imaging diagnosis. Radiology 1989;172: 749-753. 
22. Jurkovic D, Gruboeck K, Tailor A, Nicolaides KH. Ultrasound screening for congenital uterine anomalies. Br J Obstet Gynecol 1997;104:1320-1321.

23. Wu MHW, Hsu CC, Huang KE. Detection of congenital Müllerian duct anomalies using three-dimensional ultrasound. J Clin Ultrasound 1997;25:487-492.

24. Wölfer B, Salim R, Banerjee S, Elson J, Regan L, Jurkovic D. Reproductive outcomes in women with congenital uterine anomalies detected by three-dimensional ultrasound screening. Obstet Gynecol 2001;98:1099-1103.

25. Salim R, Woelfer B, Backos M, Regan L, Jurkovic D. Reproducibility of three-dimensional ultrasound diagnosis of congenital uterine anomalies. Ultrasound Obstet Gynecol 2003;21:578-582.

26. Salim R, Jurkovic D. Assessing congenital uterine Müllerian duct anomailes using three-dimensional ultrasound. Best Pract Res 2004;18:29-33.

27. Zanetti E, Ferrari LR, Rossi G. Classification and radiographic features of uterine malformations: hysterosalpingopgraphic study. Br J Radiol 1987;51:161-170.

28. Nahum GG. Uterine anomalies. How common are they, and what is their distribution among subtypes? J Reprod Med 1998;43:877-887.

29. Bermejo C, Martínez-Ten P, Cantarero R, Díaz D, Pérez Pedregosa J, Barrón E, Labrador E. Ruiz López, L. Threedimensional ultrasound in the diagnosis of Müllerian duct anomalies and concordance with magnetic resonance imaging. Ultrasound Obstetrics Gynecology 2010;35:593-601.

30. Hadden D. Double uterus and vagina. Am J Obstet Gynecol 1922;3:526-529.

31. Toaff ME, Lev-Toaff AS, Toaff R. Communicating uteri: review and classification with introduction of two previously unreported types. Fertil Steril 1984;41:661-679.

32. Lev-Toaff AS, Kim SS, Toaff R. Communicating septate uterus with double cervix: a rare malformation. Obstet Gynecol 1992;79:828-830.

33. Bonilla F, El cuello Fetal. En Bonilla-Musoles F. El cuello uterino y sus enfermedades. Ed Jims. Barcelona 1978. page 91-102, ISBN 84-7092-172-X.

34. Bonilla F, Raga F, Casañ EM, Bonilla-Musoles F. Uteroscomunicantes: Raras anomalías Müllerianas. Obstet Ginecol Españ 1999;8:127-130.

35. Fedele L, Dorta M, Brioschi D, Massari C, Candini GB. Magnetic resonance evaluation of double uteri. Obstet Gynecol 1989;74:844-847.

36. Pellerito JS, McCarthy SM, Doyle MB, Glickman MG, Decherney AH. Diagnosis of uterine anomalies: relative accurccy of MR imaging, endovaginal sonography, and hysterosalpingography. Radiology 1992;183:795-802.

37. Fischetti SG, Politi G, Lomeo E, Garozzo G. Magnetic resonance in the evaluation of Müllerian duct anomalies. Radiol Med 1995;89:105-111.

38. Deutch TD, Abuhamad AZ. The role of three-dimensional ultrasonography and magnetic resonance imaging in the diagnosis of Müllerian duct anomalies: a review of the literature. J Ultrasound Med 2008;27:413-423.

39. Carrascosa P, Capuñay C, Mariano B, López EM, Jorge C, Borghi M, Sueldo C, Papier S. Virtual hysteroscopy by multidetector computed tomography. Abdom Imaging 2008; 33:381-387.

40. Carrascosa P, Capuñay C, Baronio M, Martín López E, Vallejos J, Borghi M, Sueldo C, Papier S. Row multidetector CT virtual hysterosalpingography. Abdom Imaging 2009,34:121-133.
41. Carrascosa PM, Capunay C, Vallejos J, Martín López EB, Baronio M, Carrascosa JM. Virtual hysterosalpingography: a new multidetector $\mathrm{CT}$ technique for evaluating the female reproductive system. Radiographics 2010,30:643-661.

42. Carrascosa P, Capuñay C, Vallejos J, Baronio M, Carrascosa J. Virtual hysterosalpingography: experience with over 1000 consecutive patients. Abdom Imaging 2011;36:1-14.

43. Carrascosa P, Sueldo C, Capuñay C, Baronio M, Papier S. Virtual hysterosalpingography in the diagnosis of bicornuate versus septate uterus. Fertil Steril 2011,96:1190-1192.

44. Celik O, Karakas HM, Hascalik S, Tagluk ME. Virtual hysterosalpingography and hysteroscopy: assessment of uterine cavity and fallopian tubes using 64-detector computed tomography data sets. Fertil Steril 2010;93:2383-2384.

45. Mintz MC, Grumbach K. Imaging of congenital uterine anomalies. Ultrasound CT MR 1988;9:167-171.

46. Daya S. Ultrasonographic evaluation of uterine anomalies. In: Jaffe R, Pierson RA, Abramowics JS, editors. Imaging in infertility and reproductive endocrinology. Philadelphia JB. Lippincott 1994:63-91.

47. Fedele L, Ferrazzi E, Dorta M, Vercellini P, Candiiani GB. Ultrasonogrophy in the diferential diagnosis of arouote uteri. Fértil Steril 1988;50:361-364.

48. Fedele L, Bianchi S, Di Nola, G Franchi D, Candini GB. Endometriosis and non-obstructive Müllerian anomalies. Obstet Gynecol 1992;79:515-517.

49. Kupesic S, Kurjak A. Diagnosis and treatment of the septate uterus. Croat Med J 1998;39:185-190

50. Kupesic S, Kurjak A. Septate uterus. Detection and prediction of obstetrical complications by different forms of ultrasonography. J Ultrasound Med 1998;17:631-636.

51. Kupesic S, Plavsic BM. 2D and 3D hysterosalpingo-contrastsonography in the assessment of uterine cavity and tubal patency. Eur J Obstet Gynecol Reprod Biol 2007;133:64-69.

52. Kurjak A, Kupesic S, Schulman H, Zalud I. Transvaginal color flow Doppler in the assessment of ovarian and uterine blood flow in infertile women. Fertil Steril 1991;56:870-873.

53. Bonilla-Musoles F, Simón C, Serra V, Sampaio M, Remohi J. An assessment of hysterosalpingosonogrophy (HSSG) as a diagnostic tool for the uterine cavity defects and tubal patency. J Clin Ultrasound 1992;20:175-181.

54. Bonilla-Musoles F, Raga F, Osborne NG, Blanes J, Coelho F. Three-dimensional hysterosonography for the study of endometrial tumors: comparison with conventional transvaginal sonography, hysterosalpingography, and hysteroscopy. Gynecol Oncol 1997;65:245-252.

55. Schlief R, Deichert U. Hysterosalpingo-contrast-sonography: results of a clinical trial with new ultrasound contrast medium in 120 patients. Radiology 1991;178:213-215.

56. Bonilla-Musoles F, Raga F, Blanes J, Osborne NG, Siles CH. The use of three-dimensional ultrasound in reproductive medicine: preliminary report. Hum Reprod Update 1995; 1:3-8.

57. Bonilla-Musoles F, Pellicer A, Raga F, Osborne NG. Threedimensional (3D) ultrasound in reproduction, obstetrics and gynecology. J Assist Reprod Rev 1995;5:170-188.

58. Bonilla-Musoles F, Raga F, Blanes J, Osborne NG. Threedimensional ultrasound evaluation of ovarian masses. Gynecol Oncol 1995;59:129-135.

59. Bonilla-Musoles F. Ecografia vaginal Doppler y tridimensión. Panamericana Ed. Madrid 2004, ISBN 978-84-93.35-15-9. 
60. Bonilla-Musoles F, Dolz M, Raga F, Moreno J. Reproducción asistida: Manejo en la práctica clínica. Panamericana Ed. Madrid 2009, ISBN 978-84-98.35-156-159.

61. Bonilla-Musoles F, Raga F, Bonilla Jr F, Esquembre MJ, Castillo JC, Martin Lopez N. El diagnóstico de las anomalías Müllerianas y la ecografía 3D/4D. Cuadernos Med Reprod (Madrid) 2013;19:27-43.

62. Nicolini U, Bellotti M, Bonazzi B, Zamberletti D, Candiani, GB. Can ultrasound be used to screen uterine malformations? Fertil Steril 1987;47:89-93.

63. Ludwin A, Ludwin I, Pityński K, Banas T, Jach R. Role of morphologic characteristics of the uterine septum in the prediction and prevention of abnormal healing outcomes after hysteroscopicmetroplasty. Hum Reprod 2014;16:1-12.

64. Ludwin A, Ludwin I, Kudla M, Pitynski K, Banas T, Jach R, Knafel A. Diagnostic accuracy of three-dimensional sonohysterography compared with office hysteroscopy and its interrater/intrarater agreement in uterine cavity assessment after hysteroscopicmetroplasty. Fertil Steril 2014; 101:1392-1399.

65. Bermejo C, Martínez-Ten P, Recio M, Ruiz López L, Díaz $\mathrm{D}$, Illescas T. Three-Dimensional ultrasound and magnetic resonance imaging assessment of cervix and vagina in women with uterine malformations. Ultrasound Obstet Gynecol 2014;43:336-345.

66. Carrington BM, Hricak N, Nuruddin RN, Secaf E, Laros RK. Müllerian duct anomalies: MR imaging evaluation. Radiology 1990;176:715-719.

67. Raga F, Bonilla-Musoles F, Blanes J, Bailao 1, Osborne NG. Uterine anomalies with three-dimensional ultrasound (Müllerian duct malformations). Assist Reprod Rev 1996; 3:126-141.

68. Raga F, Bonilla-Musoles F, Blanes J, Osborne NG. Congenital Müllerian anomalies: diagnosis accuracy of threedimensional ultrasound. Fertil Steril 1996;65:523-528.

69. Raga F, Bonilla-Musoles F, Blanes J, Osborne N. Accuracy of three-dimensional ultrasound diagnosis in congenital Müllerian anomalies. Fertil Steril 1996;65:523-528.

70. Raga F, Osborne N, Bonilla Jr. F, Bonilla-Musoles F. Malformaciones Müllerianas 3D-4D Cuadernos. Med Reprod (Madrid) 2011;17:63-75.

71. Salim R, Regan B, Woelfer B, Backos M, Jurkovic D. A comparative study of the morphology of congenital uterine anomalies in women with and without a history of recurrent first trimester miscarriage. Hum Reprod 2003;18:162-166.

72. Timor-Tritsch IE, Monteagudo A, Tsymbal T, Strok I. Threedimensional inversion rendering: a new sonographic technique and its use in Gynecology. J Ultrasound Med 2005; 24:681-688.

73. Steiner H, Staudach A, Spitzer D, Schaffer H. Threedimensional ultrasound in obstetrics and gynecology: technique, possibilities and limitations. Human Reproduction 1994;9:1773-1778.

74. Sohn C, Bastert G. Die dreidimensionale UltraschallDiagnostik Springer Ed. 1994. Berlin. ISBN: 3-540-56034-3.
75. Jurkovic D, Giepel A, Gruboeck K, Jauniaux EC, Natucci Campbell S. Three-dimensional ultrasound for the assessment of uterine anatomy and detection of congenital uterine anomalies: a comparison with hysterosalpingography and two-dimensional sonography. Ultrasound Obstet Gynecol 1995;5:233-237.

76. Bermejo C, Cantarero R, Díaz D, Labrador E. Ruiz López, L. Three-dimensional ultrasonography in the diagnosis of Müllerian duct anomalies. DSJUOG 2009;3:21-30.

77. Alcázar JL. Three-dimensional ultrasound in Gynecology: current status and future perspectives. Curr Womens Health Rev 2005;1:1-14.

78. Raine-Fenning N, Fleischer AC. Clarifying the role of threedimensional transvaginal sonography in reproductive medicine: an evidence-based appraisal. J Exp Clin Assist Reprod 2005;2:10-17.

79. Mohamed M, Momtaz MD, Alaa N, Ebrashy MD, Ayman A, Marzouk MD. Three-dimensional ultrasonography in the evaluation of the uterine cavity. MEFS J 2007;12:41-46.

80. Ghi T, Casadio P, Kuleva M, Perrone AM, Savelli L, Gianchi S, Pelusi C, Pelusi G. Accuracy of three-dimensional ultrasound in diagnosis and classification of congenital uterine anomalies. Fertil Steril 2009;92:808-813.

81. Zohav E, Melcer Y, Tur-Kaspa I, Rabinson J, Anteby EI, Orvieto R. The role of three-dimensional ultrasound for the diagnosis of congenital uterine anomalies. Open J Obstet Gynecol 2011;1:239-242.

82. Caliskan E, Ozkan S, Cakiroglu Y, Sarisoy HT, Corakci A, Ozeren S. Diagnostic accuracy of real-time 3D sonography in the diagnosis of congenital Müllerian anomalies in highrisk patients with respect to the phase of the menstrual cycle. J Clin Ultrasound 2010;38:123-127.

83. Bonilla-Musoles F, Tortajada M. Uteros comunicantes Rev, Españ. Obstet Gynecol 1979;38:105-111.

84. La Torre R, Prosperi Porta R, Franco C, Sansone M, Mazzocco M, Pergolini I, De Felice C, Cosmi EV. Three-dimensional sonography and hysterosalpingosonography in the diagnosis of uterine anomalies. Clin Exp Obstet Gynecol 2003;30:190-192.

85. Whitehouse GH, Wright $\mathrm{CH}$. Imaging in gynecology. In: Grainger RG, Allison DJ, editors. Diagnostic Radiology 1902; 92:1825-1853.

86. Sorensen SS. Hysteroscopic evaluation and endocrinological aspects of women with Müllerian anomalies and oligomenorrhea. Internal J Fertil 1987;32:445-452.

87. McBean JH, Brumsted JR. Septare uterus with cervical duplication: a rare malformation. Fertil Steril 1994;62:415-417.

88. Imboden S, Müller M, Raio L, Müeller MD, Tutschek B. Klinischebedeutung des 3d-Ultraschalls neben MRI beiuterinen Fehlbildungen. Ultraschall in Med 2014;35: 440-444.

89. Grimbizis GF, Gordts S, Di SpiezioSardo A, Brucker S, De Angelis C, Gergolet M, Li TC, Tanos V, Brölmann H, Gianaroli $\mathrm{L}$, et al. The ESHRE-ESGE consensus on the classification of femalegenital tract congenital anomalies. Gynecol Surg 2013; 10:199-212. 